\title{
The interplay between emotion and cognition in autism spectrum disorder: implications for developmental theory
}

\section{Sebastian B. Gaigg*}

Department of Psychology, Autism Research Group, City University London, London, UK

\section{Edited by:}

Lihong Wang, Duke University, USA

Reviewed by:

Geoff Bird, Birkbeck College, UK

Coralie Chevallier, Children's Hospital

of Philadelphia, USA

Liz Pellicano, Institute of Education,

UK

\section{*Correspondence:}

Sebastian B. Gaigg, Department of Psychology, Autism Research Group, City University London, Northampton Square, London EC1V OHB, UK.

e-mail: s.b.gaigg@city.ac.uk

\begin{abstract}
Autism Spectrum Disorder (ASD) is a neurodevelopmental disorder that is clinically defined by abnormalities in reciprocal social and communicative behaviors and an inflexible adherence to routinised patterns of thought and behavior. Laboratory studies repeatedly demonstrate that autistic individuals experience difficulties in recognizing and understanding the emotional expressions of others and naturalistic observations show that they use such expressions infrequently and inappropriately to regulate social exchanges. Dominant theories attribute this facet of the ASD phenotype to abnormalities in a social brain network that mediates social-motivational and social-cognitive processes such as face processing, mental state understanding, and empathy. Such theories imply that only emotion related processes relevant to social cognition are compromised in ASD but accumulating evidence suggests that the disorder may be characterized by more widespread anomalies in the domain of emotions. In this review I summarize the relevant literature and argue that the social-emotional characteristics of ASD may be better understood in terms of a disruption in the domain-general interplay between emotion and cognition. More specifically I will suggest that ASD is the developmental consequence of early emerging anomalies in how emotional responses to the environment modulate a wide range of cognitive processes including those that are relevant to navigating the social world.
\end{abstract}

Keywords: autism, emotion, social-motivation, social brain, social cognition

\section{INTRODUCTION}

Ever since the behavioral syndrome now recognized under the rubric of the Autism Spectrum was first described more than six decades ago, it has been noted that atypicalities in reciprocal emotion related behaviors constitute a hallmark feature of its clinical presentation. Both Kanner (1943) and Asperger (1944) identified difficulties in this domain as a unifying characteristic amongst the cases they described, and to this day diagnostic instruments and screening tools consider anomalies in emotional reciprocity as a clinically significant indicator of the disorder (Schopler et al., 1980; Lord et al., 1989, 1994; Robins et al., 2001). For as long as disturbances in affective processes have been considered central to the clinical phenotype of Autism Spectrum Disorder (ASD), however, their significance in the development of the disorder has remained a matter of debate. Kanner (1943) and Asperger (1944) originally disagreed over whether they had identified a biologically determined disorder of interpersonal affect or a particular personality trait. During the 1950s and 1960s views diverged over the misguided concern of whether the primary caretakers might be to blame for their child's emotional withdrawal or not, and most recently the dispute has turned to the question of whether early emerging impairments in social-cognitive processes are responsible (e.g., Baron-Cohen, 1995, 2005; Frith, 2003; Schultz, 2005), or whether Kanner's (1943) original emphasis on innately specified interpersonal affective processes may have been correct after all (e.g., Hobson, 2002; Loveland, 2005; Chevallier et al., 2012). As diverse as the ideas have been over the decades, they have all shared the view that emotion related difficulties in ASD are to be understood with reference to atypicalities in social processes. In this review I will question this position and suggest instead that the social-emotional characteristics of the disorder are more fruitfully conceptualized in terms of domain-general anomalies in how the influences of emotions on cognition, that sometimes augment and at other times attenuate experiences of the world, organize what an infant learns about salient events in a complex and dynamically changing environment. In the context of the broader issues under consideration in this Special Topic, the study of ASD is therefore of considerable interest as it sheds light on a critical developmental function of the interplay between emotion and cognition.

The Autism Spectrum comprises a set of related pervasive developmental disorders (PDDs) that are all characterized by atypicalities in the domains of communication and socialization and by a restricted and repetitive pattern of interests and activities (Wing and Gould, 1979; American Psychiatric Association, 2000). The disorders subsumed under this spectrum include Autistic Disorder, Asperger's Disorder, and PDD-Not Otherwise Specified (PDD-NOS), which together affect approximately $1 \%$ of the population and are around three to four times more common in males than females (Bertrand et al., 2001; Baird et al., 2006). All subtypes of ASD share a uniquely patterned cognitive profile that includes difficulties in understanding behaviour in terms of mental states, such as beliefs and desires (Baron-Cohen et al., 1985; Baron-Cohen, 1995; Frith, 2003), difficulties in deploying cognitive resources flexibly in order to plan and execute goal directed 
behaviors (Ozonoff et al., 1991a; Hill, 2004), a tendency to process information in a piecemeal and perceptually driven rather than holistic and conceptually driven fashion (Shah and Frith, 1993; Mottron and Burack, 2001; Frith, 2003; Mottron et al., 2006) and a characteristic profile of memory strengths and weaknesses that parallels that seen in neuropathologies of the frontal and/or medial-temporal lobes (Boucher and Bowler, 2008; Boucher et al., 2012). Since there is little evidence to support a nosological differentiation of subtypes of autistic pathologies (see Wing and Gould, 1979; Wing, 1993; Prior et al., 1998; Volkmar et al., 2004; Bowler, 2007 for discussion), the forthcoming edition of the Diagnostic and Statistical Manual of Mental Disorders $5^{1}$ will include only the single category of "ASD," which will be the preferred term used throughout this review. I will describe individuals who have received a diagnosis of an ASD as autistic individuals rather than individuals with autism to reflect the preferred terminology of those who are on the spectrum (see Pellicano et al., 2011).

In relation to emotions, the view I adopt in this review is informed by several influential authorities in the field (e.g., James, 1890; Cannon, 1927; Schachter and Singer, 1962; Reisenzein, 1983; Lazarus, 1984; Zajonc, 1984; Ekman, 1992; Levenson, 1992; Damasio, 1994, 1999, 2003; LeDoux, 1996, 2002; Lane and Nadel, 2000; Russell, 2003; Lane, 2006; Barrett et al., 2007). I will use the words "emotion(al)" and "affect(ive)" in a theoretically neutral sense to describe the phenomena that accompany situations that tend to elicit approach and avoidance behaviors. The term "arousal" will denote automatic changes in physiological parameters such as heart rate, skin conductance, or pupil dilation that occur during (but are not specific to) emotional episodes. Although arousal is also often used to describe changes in brain activity (e.g., cortical arousal), I will restrict my discussion here to changes in peripheral nervous system activity that are, broadly speaking, open to conscious awareness. The word "feeling" will be used to describe the subjective experience that people report when they are asked about their emotional state. It does not comprise "feelings" of mere physical sensations (e.g., I feel cold) or homeostatic imbalances (e.g., I feel sick) although the two are closely related. The critical difference is that emotional feelings necessarily involve an evaluation (often termed appraisal) of arousing events whilst physical feelings are primarily conscious perceptions of the body's internal milieu. The nature of the evaluative process in question in this context remains the matter of debate but most authors agree that it is intricately linked to self-awareness and consciousness on the one hand and self-preservation on the other (e.g., LeDoux, 2002; Damasio, 2003; Lane, 2006). More specifically, stimulus induced arousal is thought to shape (or elicit) perceptions of arousing objects or events in terms of their value (innately specified or learned) to the wellbeing (physical or psychological) of the Self, which modifies how the Self is expressed in consciousness (e.g., as feeling afraid). Finally, it is important to note that this review will not deal with the topic of mood. Although moods and emotions are closely related, only emotions are intentional in the philosophical sense of being about something and the focus of this paper is on how autistic

\footnotetext{
${ }^{1} \mathrm{~A}$ draft version of the DSM-V can be found here http://www.dsm5.org/
} proposedrevisions/pages/proposedrevision.aspx? $\mathrm{rid}=94$ individuals experience, understand, and relate to the objects and events in the world that emotions are about.

\section{THE SOCIAL-EMOTIONAL DIFFICULTIES ASSOCIATED WITH ASD}

Although emotion related processes have been of interest in relation to ASD since Kanner (1943) first described the syndrome, work in this area has almost exclusively focused on the processes and behaviors that serve to regulate interpersonal conduct. Within this narrow focus, the literature is vast, covering more than 100 empirical papers and a broad theoretical literature. Doing justice to this work in the space available is difficult and I must therefore apologize to all authors whose views I have caricatured in the service of brevity. Fortunately, the three points I want to make in this section are relatively uncontroversial. The first is, that it is widely accepted that ASD is characterized by difficulties in multiple facets of interpersonal emotional communication. The second, that dominant explanations of these difficulties attribute them to anomalies in the development of broader reciprocal social competences. And the third, that these reciprocal social competences are mediated by a network of cortical and sub-cortical regions that collectively constitute what has often been called the "social brain."

\section{THE EVIDENCE}

Amongst the earliest studies to systematically assess emotion related behaviors in ASD was a series of experiments by Hobson and colleagues who showed that autistic children were limited in understanding the emotional expressions of others. Such children experienced difficulties in matching emotional expressions across facial, vocal, and gestural modalities (Hobson, 1986a,b; Hobson et al., 1988a) and they appeared not to take notice of emotional expressions when asked to sort photographs of faces in whatever way they wished (Weeks and Hobson, 1987). When they were instructed to sort faces according to their expressions, autistic children were able to do so but through a more piecemeal perceptual processing style (Hobson et al., 1988b).

The pioneering work by Hobson and colleagues remains exemplary in terms of methodological rigor and ingenuity and it also remains representative of the observations of the 100 or so studies that followed. This last conclusion may come as a surprise because brief summaries of the relevant literature in empirical papers often give the impression that it is not entirely clear whether or not autistic individuals perceive and identify emotional expressions differently. Fortunately, a recent review of the facial emotion recognition literature in ASD by Harms et al. (2010) clarifies this issue. Following their systematic scrutiny of over 40 behavioral, 7 eyetracking, and 22 brain imaging and electrophysiological studies up to 2010, Harms et al. (2010) conclude that, despite inconsistencies in behavioral observations, there is little doubt that autistic individuals extract emotions from faces differently than comparison groups. Tables 1 and 2 below are an attempt to complement Harms et al. (2010) by summarizing emotion perception studies in ASD across modes of expression. Table 1 provides a brief description of behavioral studies up to April 2012 with studies failing to demonstrate convincing group differences listed first. Table 2 summarizes 


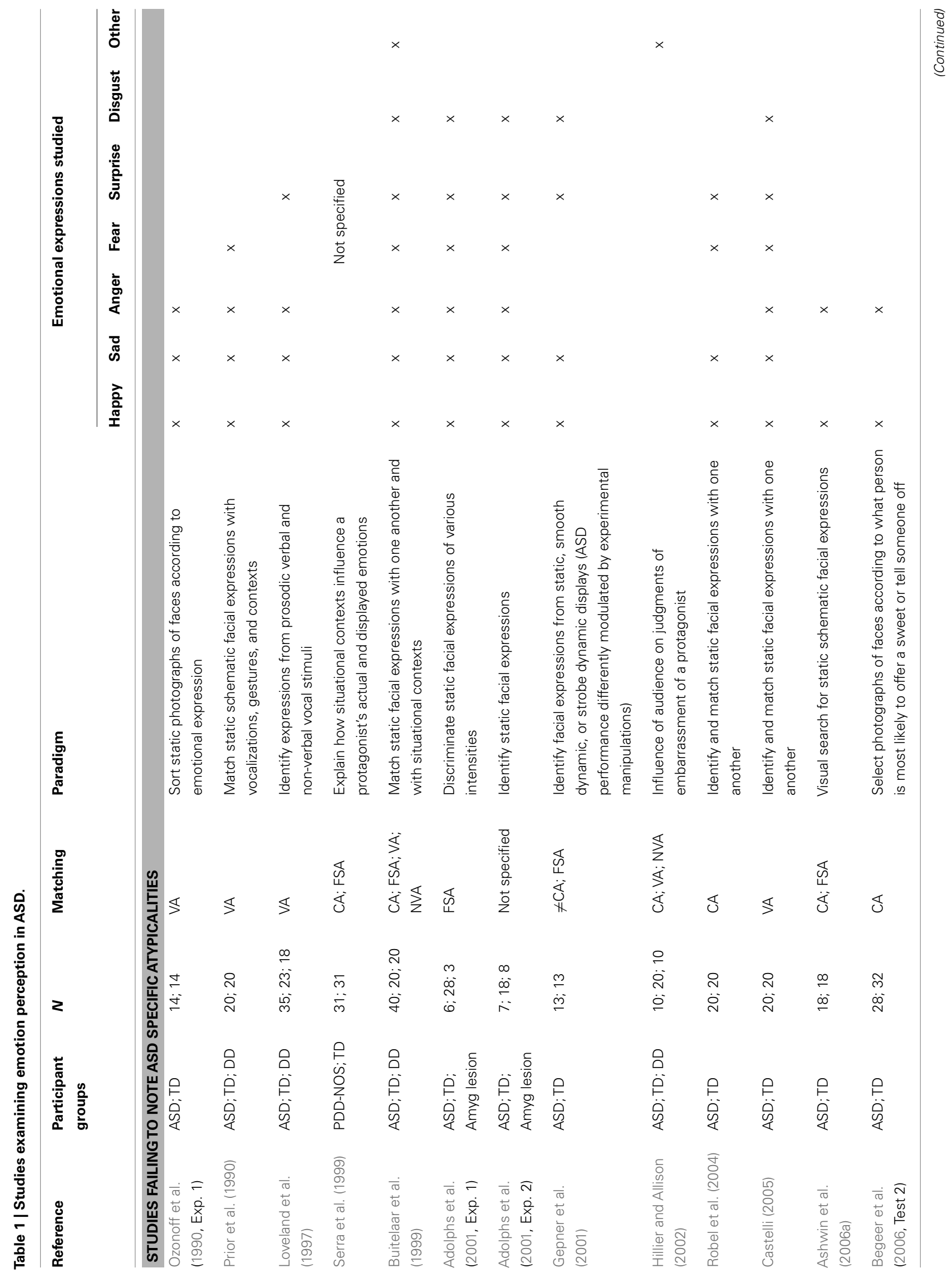




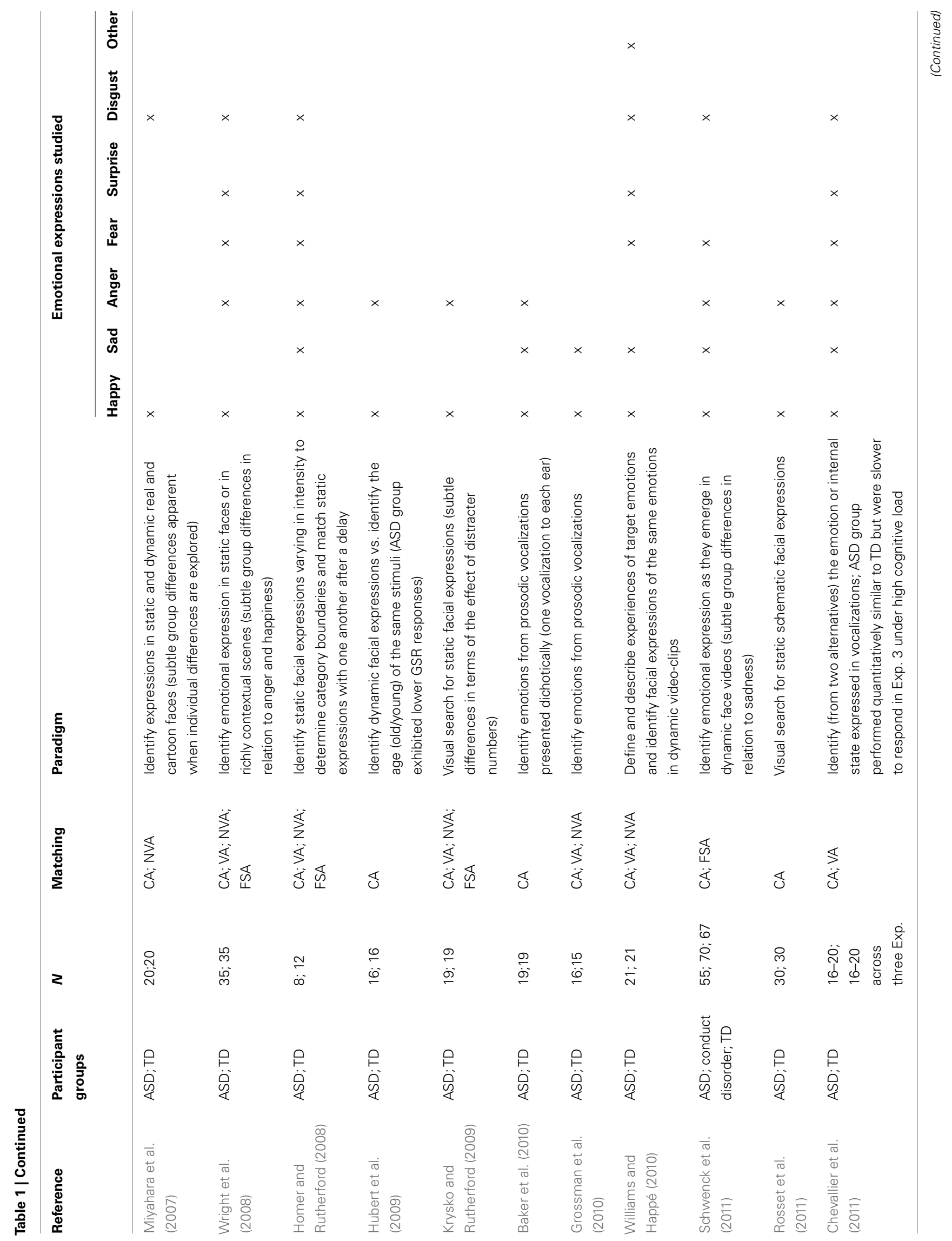




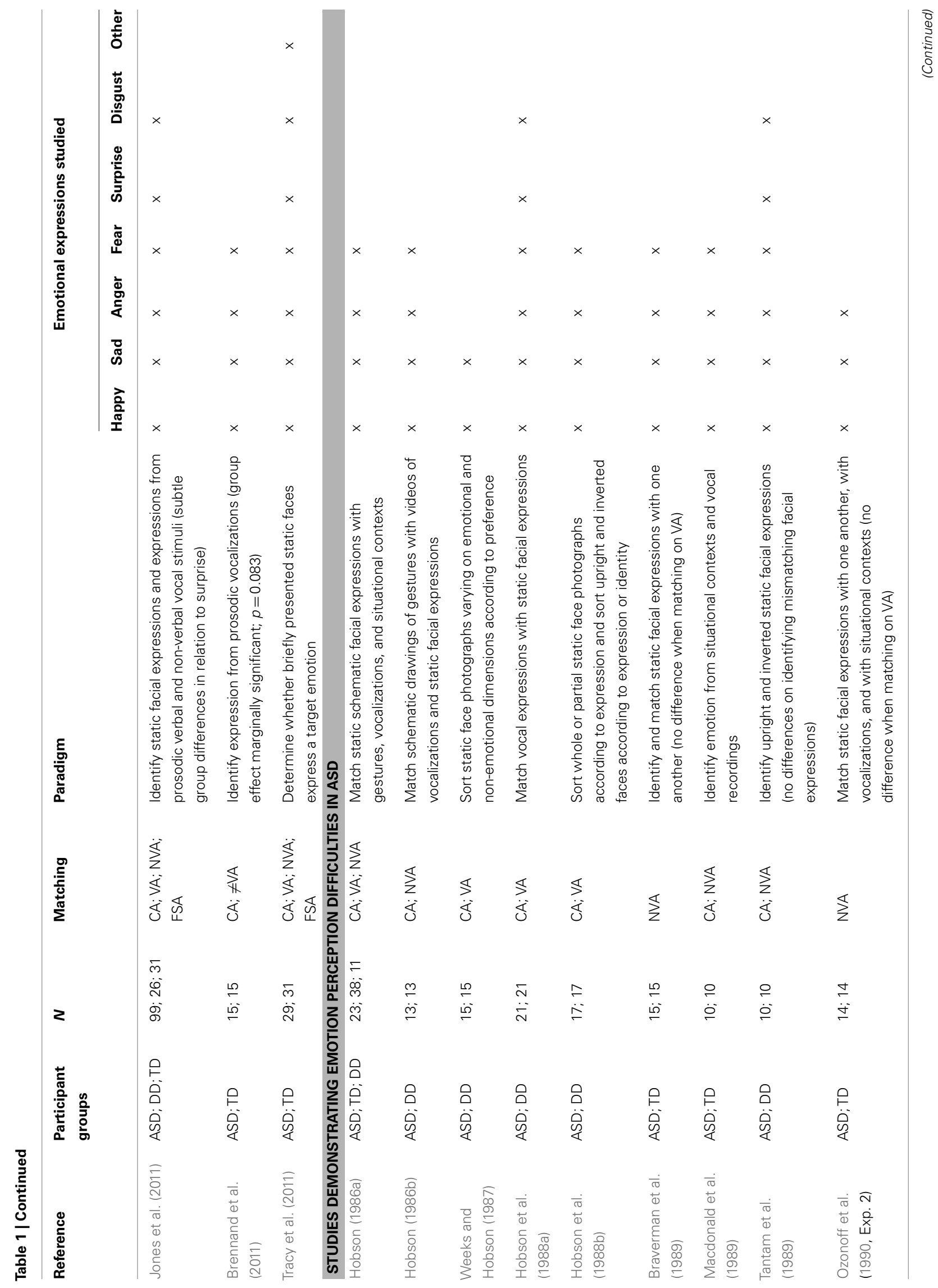




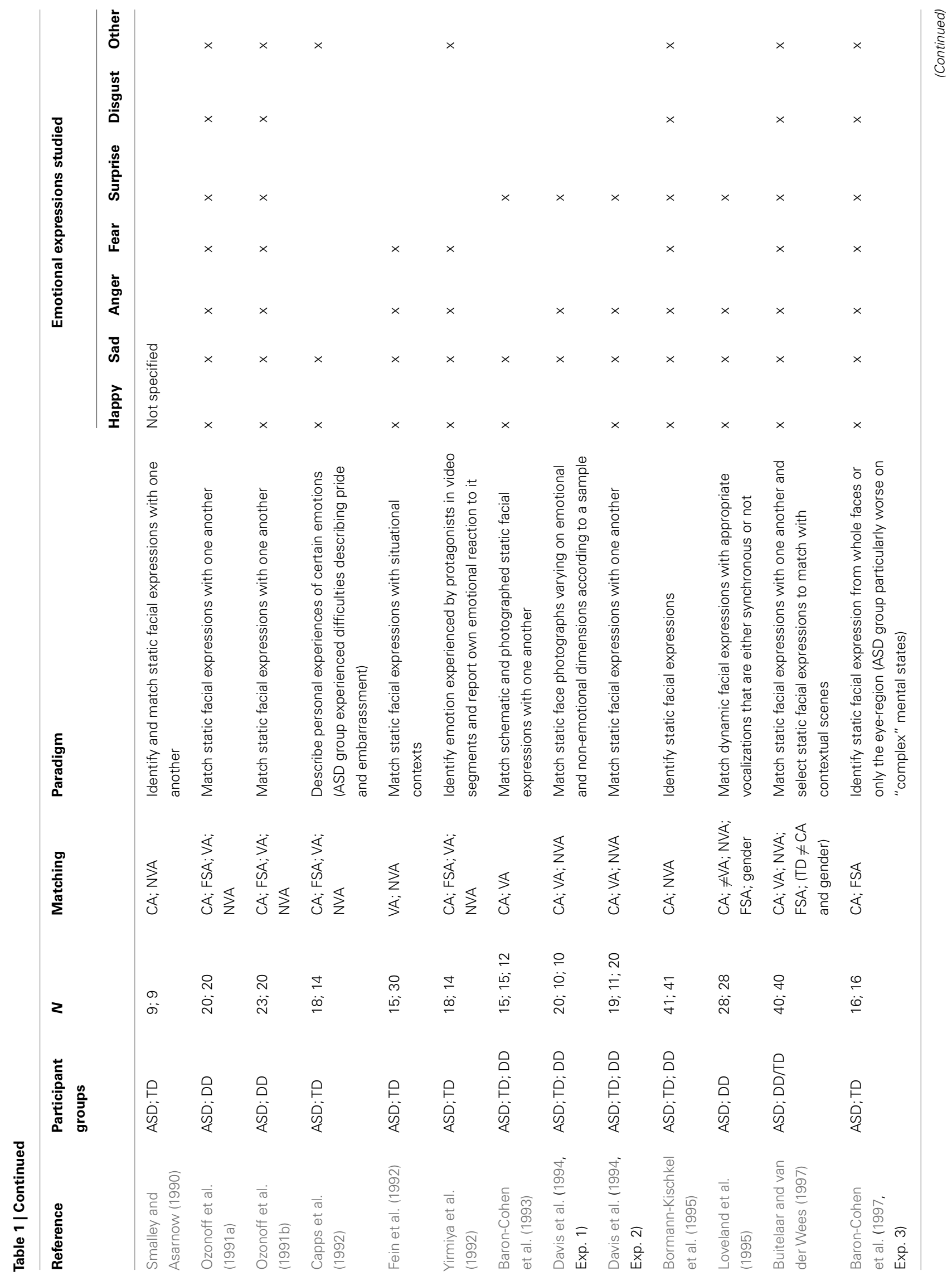




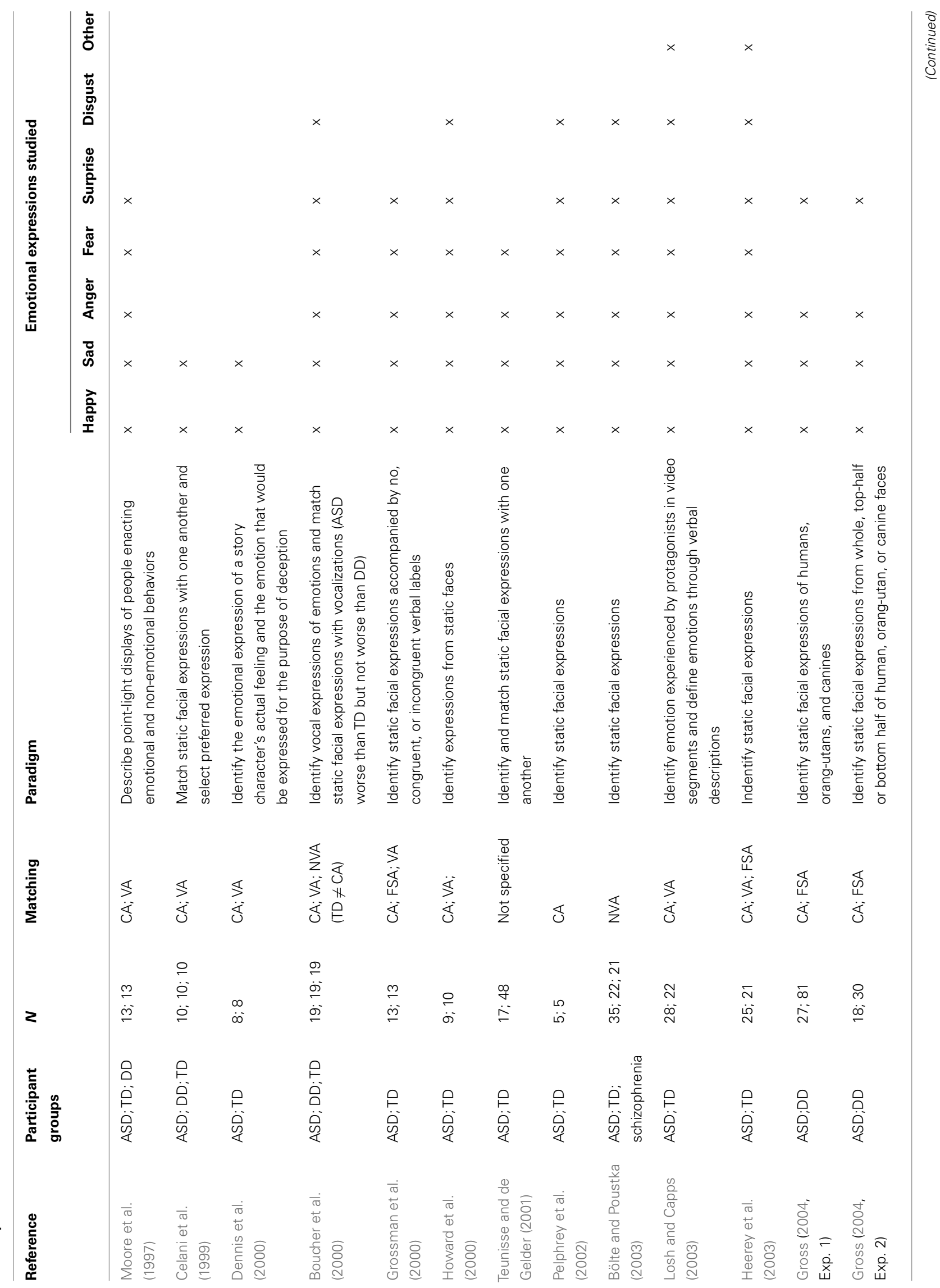




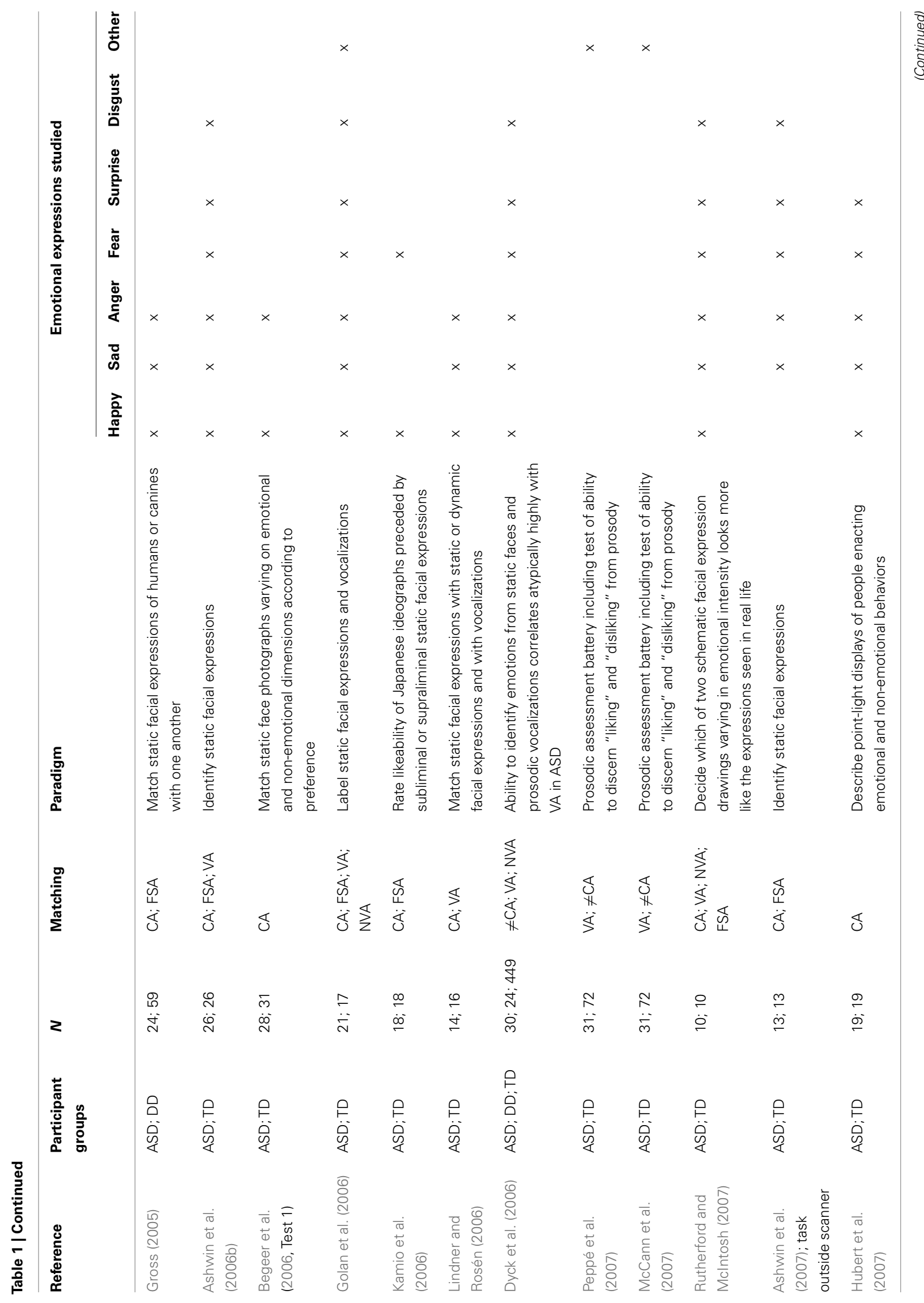




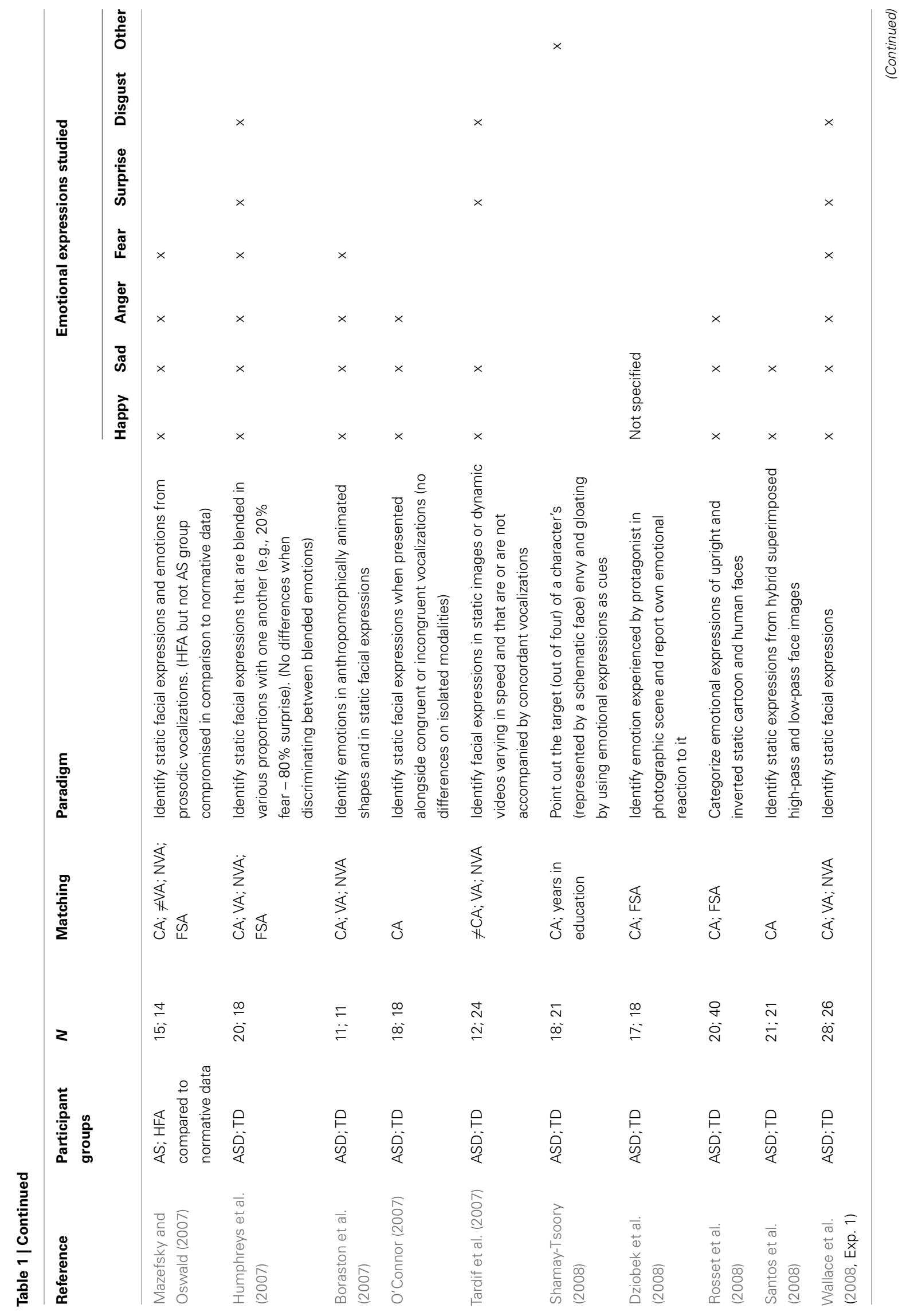




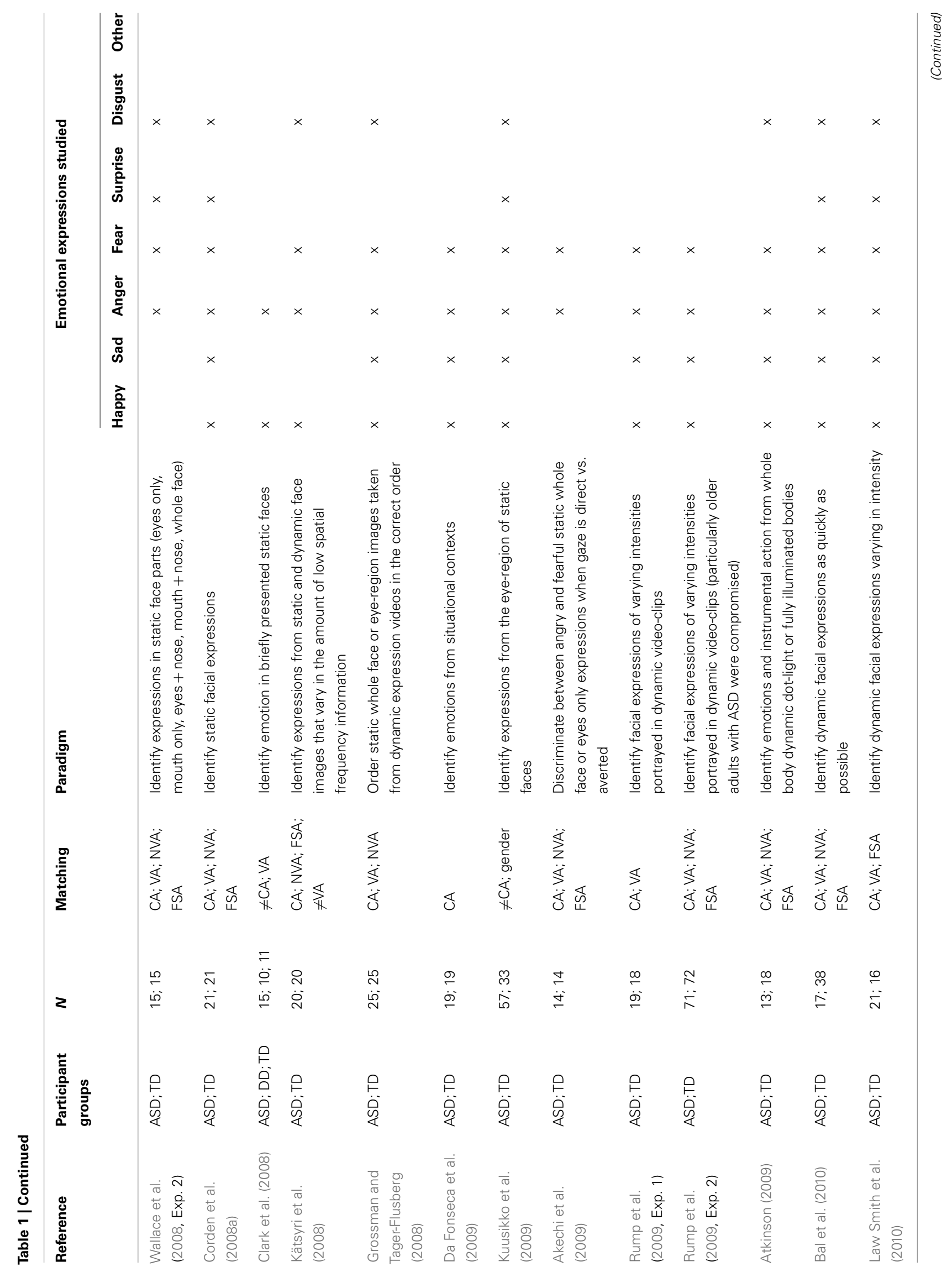




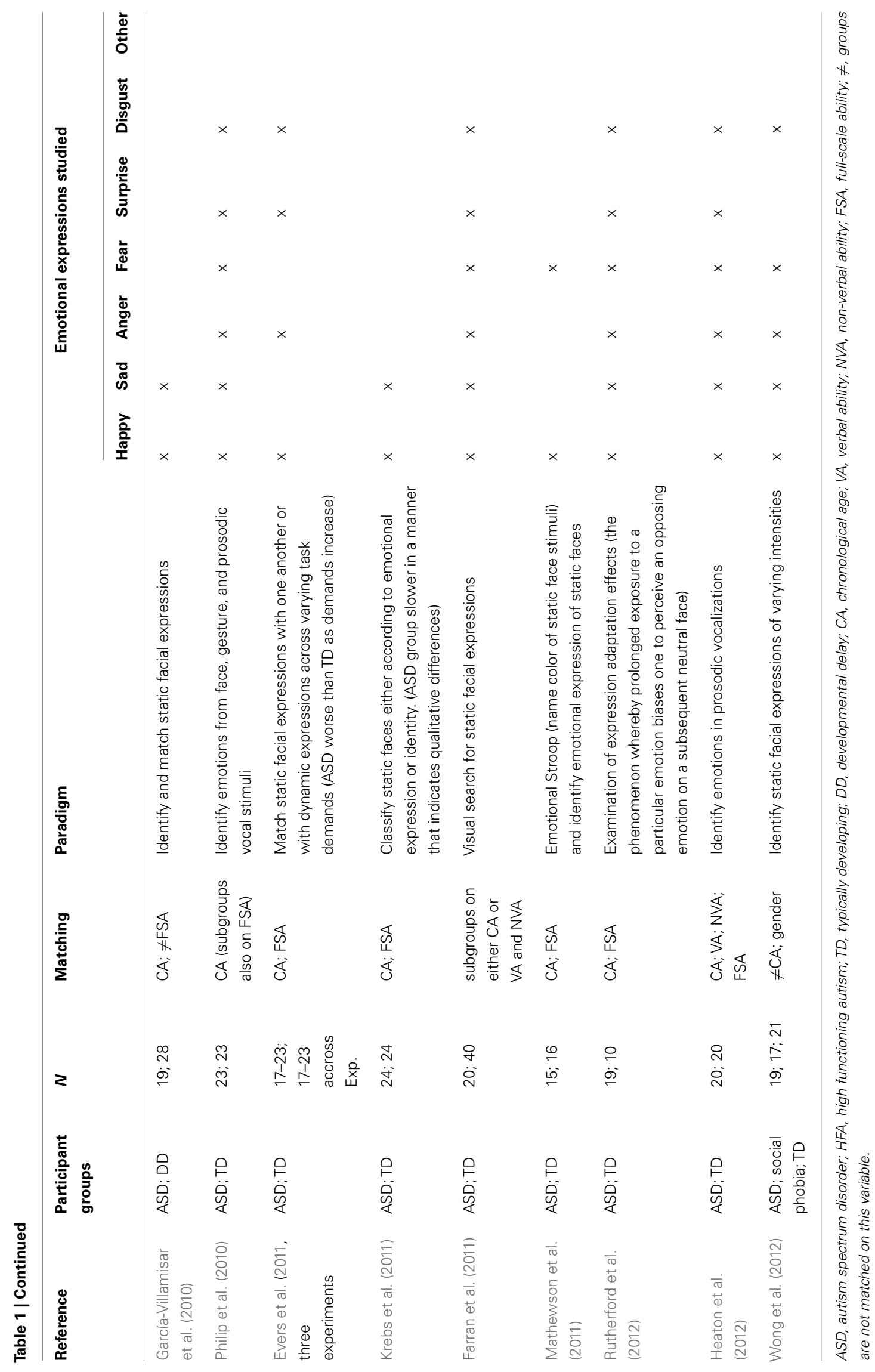




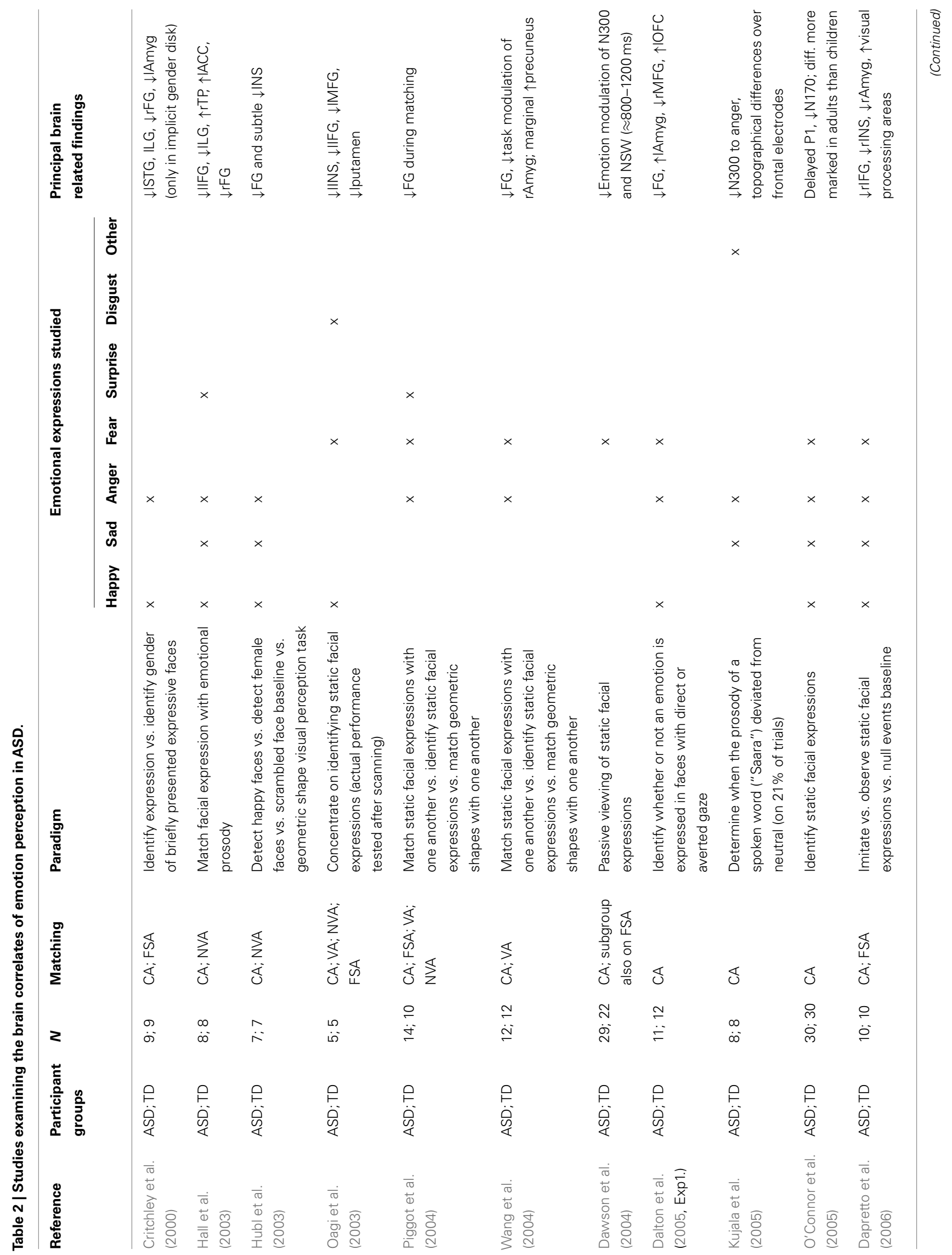




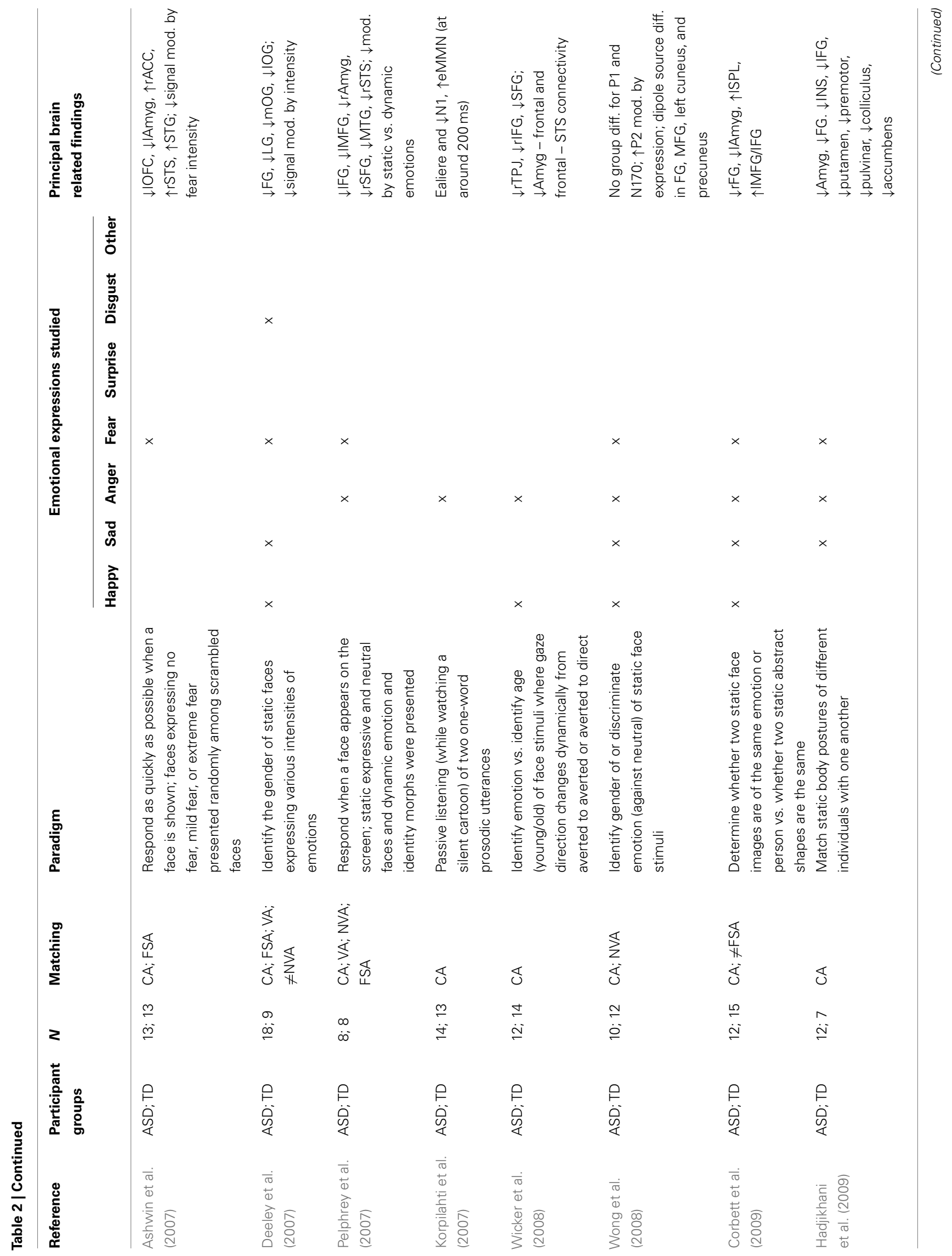




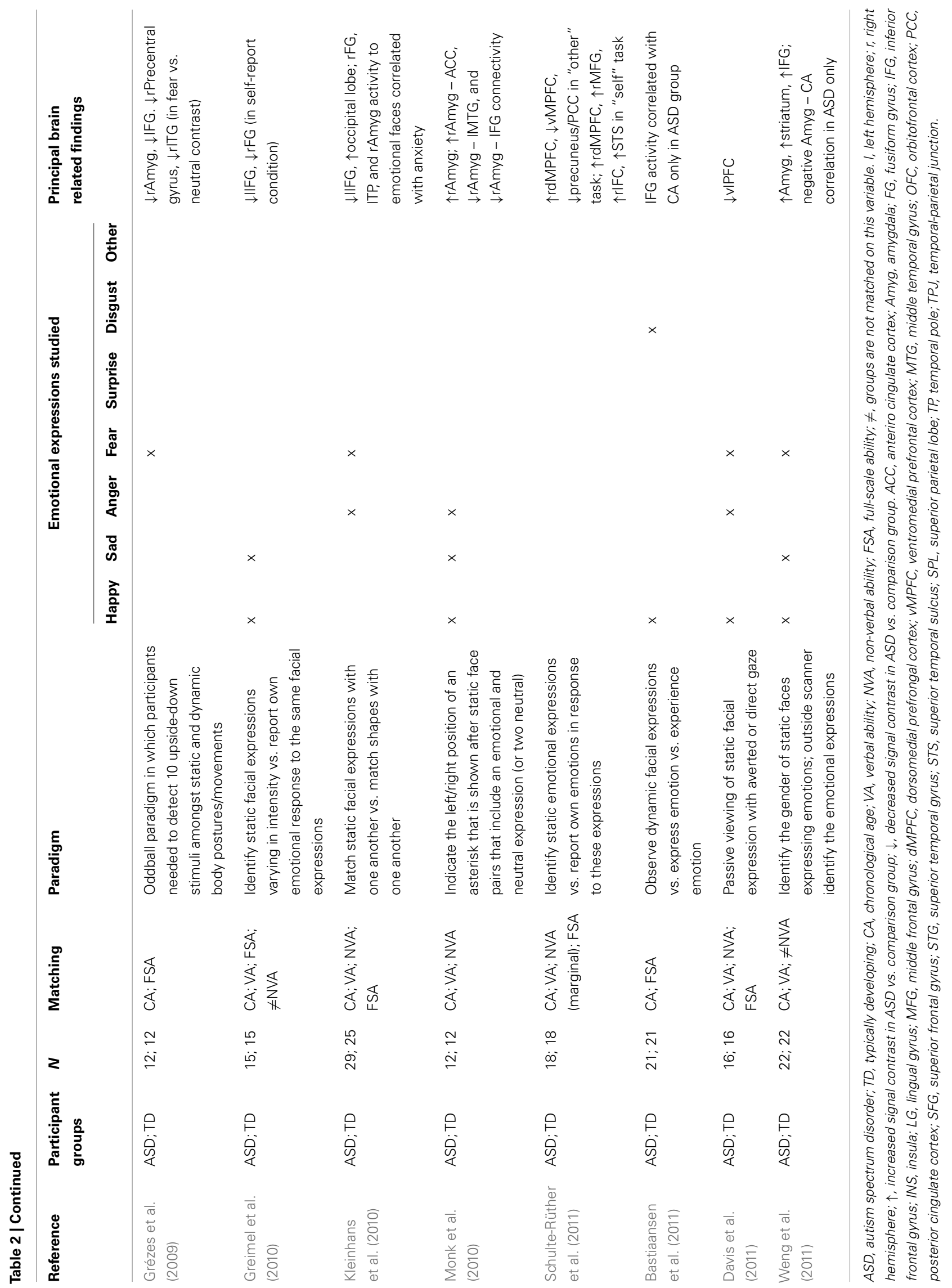


functional brain based studies for the same period ${ }^{2}$. In line with Harms et al. (2010), the available evidence reveals inconsistencies in behavioral findings with approximately one in every four studies failing to demonstrate atypical emotion perception in ASD. These inconsistencies do not appear to be systematically related to a single methodological factor such as the nature of the experimental paradigm used, the type or number of emotions studied, or sample characteristics (e.g., age, ability level) including the procedures used to match ASD and comparison groups (e.g., VA vs. NVA). In combination these factors do account for some of the inconsistencies and certain co-morbidities also appear to play a role (e.g., Cook et al., in press). Importantly, however, brain based studies reveal atypical neural correlates of emotion perception relatively consistently in ASD, suggesting that not all behavioral paradigms are sensitive to qualitative differences in how autistic individuals extract emotional information from the face. Overall therefore, the conclusions by Harms et al. (2010) in relation to facial emotion recognition hold for emotion perception on the whole, and to the best of my knowledge, no authors have ever claimed that autistic individuals identify and understand the emotional expressions of others in an entirely typical fashion.

Although studies of emotion perception are by far the most numerous, there is also a considerable literature on other facets of emotion related interpersonal behaviors in ASD (see Begeer et al., 2008 for a recent review). For instance, it is fairly consistently reported that autistic individuals are less likely than non-autistic individuals to direct emotional expressions at others during naturalistic interactions (Snow et al., 1987; Macdonald et al., 1989; Mundy and Sigman, 1989; Yirmiya et al., 1989; Dawson et al., 1990; Kasari et al., 1990, 1993; Sigman et al., 1992; Dissanayake et al., 1996; Charman et al., 1997; Joseph and Tager-Flusberg, 1997; Bieberich and Morgan, 1998; Zwaigenbaum et al., 2005; Hobson et al., 2009; Hudenko et al., 2009). Autistic individuals also tend to mimic the facial expressions of others less frequently and consistently than non-autistic individuals (McIntosh et al., 2006; Beall et al., 2008; Stel et al., 2008; Oberman et al., 2009; but, see Magnée et al., 2007; see also Sims et al., 2012) and they share the emotional experiences of others in a qualitatively different manner than comparison groups (Yirmiya et al., 1992; Baron-Cohen and Wheelwright, 2004; Lombardo et al., 2007; Rogers et al., 2007; Dziobek et al., 2008; Hobson et al., 2009; Hurdy and Slaughter, 2009; Minio-Paluello et al., 2009a; Bird et al., 2010; Greimel et al., 2010; Schulte-Rüther et al., 2011; Schwenck et al., 2011; see also the discussion between Minio-Paluello et al., 2009b; Smith, 2009). Although findings in this context are not always consistent (see Begeer et al., 2008), the weight of the evidence overall leaves little doubt that ASD is characterized by anomalies in multiple facets of interpersonal affective behaviors, and the real life consequences

\footnotetext{
${ }^{2}$ Relevant studies were identified through cited reference searches and through a combination of search terms ("ASD" or "Autism," "Emotion Perception," "Emotion Recognition") in the Web of Knowledge. Studies are only included in the tables if (a) they included a comparison group, (b) the minimum sample size was at least five ASD and five comparison participants, and (c) at least one of six basic emotions (happy, sad, angry, fear, surprise, and disgust) was studied. The last criterion was loosened somewhat to allow for the inclusion of four studies that used other concretely defined emotions of interest (Hillier and Allison, 2002; Peppé et al., 2007; McCann et al., 2007; Shamay-Tsoory, 2008).
}

of these have been documented in a series of elegant naturalistic observations by Sigman and Kasari and their colleagues (Sigman et al., 1992; Dissanayake et al., 1996; Corona et al., 1998; see also Loveland and Tunali, 1991; Bacon et al., 1998; see also Hobson et al., 2009). In these studies, children with and without a diagnosis of ASD were videoed as they interacted with an experimenter or parent who suddenly expressed distress, fear, or discomfort. Not surprisingly, children with learning difficulties and typically developing children responded to the adult's expressions by interrupting their play behavior and orienting to the adult, often with marked concern. Autistic children, on the other hand, were more inclined to keep playing with their toys even when physiological arousal responses indicated that they had registered the event at some level (Bacon et al., 1998; Corona et al., 1998). An important consequence of this was that autistic children did not acquire avoidance behaviors toward the stimuli that had elicited the negative emotions in the adult. In other words, they were not only less attentive to the emotional displays of others but also missed opportunities to learn about the hedonic significance of objects in their environment as a result.

The evidence set out thus far suggests that autistic individuals are limited in multiple aspects of emotionally patterned communication. Laboratory experiments and naturalistic observations converge in showing that emotional expressions are not particularly salient to autistic individuals and although they identify emotional expressions during some circumstances, they appear not to engage the same processes in order to do so. They also make fewer attempts to initiate emotional exchanges and together these differences afford autistic individuals fewer opportunities to share their emotional experiences with others and to learn about the hedonic significance of environmental stimuli through them (see also Hobson, 1993, 2002). That these disturbances exist and that they have consequences for the developmental trajectory of the disorder is no longer disputed. What continues to divide opinion is what causes this facet of ASD in the first place.

\section{THE THEORIES}

Many theoretical frameworks are relevant to the social-emotional characteristics of ASD, including those that identify anomalies in domain-general processes such as perception, attention, learning, and executive function as critically important in mapping the developmental trajectory of the disorder. The focus of this review, however, lies with a group of theories that consider socialemotional difficulties in ASD to be the result of atypicalities in relatively domain specific processes that operate primarily (or even exclusively) in the context social interactions ${ }^{3}$. These theories include the idea that atypicalities in the development of a neural network mediating social-motivation are responsible (e.g., Dawson and Lewy, 1989; Schultz et al., 2003; Dawson et al., 2005; Schultz, 2005; Chevallier et al., 2012), the suggestion that differences in the self regulation of behavior play a critical role (e.g., Loveland, 2005; Bachevalier and Loveland, 2006), the view that a deficient mechanism for the understanding of mental states is to blame (e.g., Leslie and Frith, 1990; Baron-Cohen, 1995;

${ }^{3}$ Readers interested in the broader theoretical literature relating to ASD should consult the exhaustive overview by Bowler (2007). 
Baron-Cohen et al., 2000; Frith, 2003) and the notion that a disruption in an infant's readiness to relate to and identify with the psychological orientations of others lies at the root of the problem (e.g., Hobson, 1993; Hobson, 2002; see also Loveland, 2005).

\section{Social-motivational accounts}

Social-motivational theories originate in observations of atypical face processing in ASD (see Weigelt et al., 2012 for a critical review). As noted above, one of the early studies by Hobson et al. (1988b) suggested that autistic children engage unusual perceptual processes to extract emotional expressions from faces, which several subsequent studies have confirmed (e.g., Tantam et al., 1989; Davis et al., 1994; Teunisse and de Gelder, 2001; Gross, 2005; Deruelle et al., 2008b). It has also become apparent, however, that atypical face processing interferes not only with the perception of emotional expressions but also with the perception of non-emotional information such as an individual's identity (e.g., Boucher and Lewis, 1992; Davis et al., 1994; Boucher et al., 1998; Joseph and Tanaka, 2003; Deruelle et al., 2008b; Wallace et al., 2008), age (Hobson, 1983; Gross, 2002, 2005), or gender (Deruelle et al., 2004). Moreover, eye-tracking studies suggest that autistic individuals fixate less on faces than non-autistic individuals when viewing complex social scenes and even when they do, they look less at the eye-region and more at the mouth or non-feature regions of the face (Klin et al., 2002; Pelphrey et al., 2002; Dalton et al., 2005; Speer et al., 2007; Spezio et al., 2007; Corden et al., 2008b; Bird et al., 2011; see Senju and Johnson, 2009 for further discussion). Broader than emotion related atypicalities in social perception are also evident in relation to biological motion (e.g., Moore et al., 1997; Blake et al., 2003; Cook et al., 2009; Koldewyn et al., 2011; Annaz et al., 2012) and vocalizations (McCann et al., 2007; Peppé et al., 2007). Thus, difficulties in the processing of emotional expressions can be seen to constitute only part of a broader anomaly in the perception and understanding of the social environment (i.e., other people).

To explain widespread social-perceptual difficulties, several authors have contributed to a social-motivational theory, which argues that a lack of motivation to attend to and interact with others early in life leads to the divergent development of a social brain network that is critical for the perception and understanding of the social environment (Grelotti et al., 2002; Schultz et al., 2003; Dawson et al., 2005; Schultz, 2005; Chevallier et al., 2012). The basic tenets of this account are the following. First, that human interaction is inherently rewarding. Second, that ASD is the result of a dysfunctional neural network comprising the amygdala, striatum, and orbital-frontal cortex that mediates both the experience and seeking of such reward. Third, that the consequence of this dysfunction is that autistic infants orient less to the social environment, thus compromising the maturation of a broader social brain network that encompasses areas critical for face processing (e.g., Fusiform Gyrus; see Kanwisher, 2000), mental state understanding (Superior Temporal Sulci, Medial Prefrontal Cortex, Temporal Poles, see Gallagher and Frith, 2003), and empathy/interpersonal affective behaviors (Anterior Cingulate Cortex, Anterior Insula, Amygdala, Striatum; see Baron-Cohen, 2005; Singer, 2006; Singer and Lamm, 2009). And finally, social-motivational accounts argue that it is the dysfunction of this broader social brain network that ultimately yields the clinically defining reciprocal social impairments of ASD, including the difficulties we, see in social-emotional behaviors. This account is consistent with a large body of evidence (Schultz, 2005; see Dawson et al., 2005; Grossmann and Johnson, 2007; Chevallier et al., 2011 for relevant reviews) that I will return to in more detail shortly when considering the concept of a "social brain" more closely.

\section{The behavioral self regulation account}

The view put forward by Loveland and colleagues (Loveland, 2001, 2005; Bachevalier and Loveland, 2006) in many ways complements the social-motivational view. Loveland points out that ASD is characterized by difficulties not only with respect to the perception of social-emotional signals but also with regards to the regulation of behavior in response to these signals. At first, this may seem a trivial point since it should come as no surprise that an individual who experiences difficulties in perceiving certain properties of the world should also respond to these properties differently. Loveland's arguments, however, are far from trivial, because they stress that perception and action are intimately linked (see MerleauPonty, 1964; Fogel, 1993 for additional discussion). Perceiving the emotional significance of someone else's facial and postural expressions is of little use if one does not know how to respond appropriately, and not understanding the behavioral affordances of emotional signals may be reason enough not to attend to them in the first place. Thus social-emotional difficulties in ASD may not arise because of a lack of motivation per se but because of a lack of understanding what emotional signals afford. Support for this argument stems from the studies by Sigman and Kasari and colleagues outlined earlier in which autistic children were consistently less responsive to the emotional displays of others (Loveland and Tunali, 1991; Sigman et al., 1992; Yirmiya et al., 1992) despite demonstrating an awareness of the emotional displays in question (Bacon et al., 1998; Corona et al., 1998). The behavioral self regulation view is also in line with studies that demonstrate typical physiological but atypical behavioral separation anxiety in autistic children (Willemsen-Swinkels et al., 2000; Sigman et al., 2003) and more generally it helps to explain why studies of emotion perception tend to yield less consistent behavioral differences between ASD and non-ASD groups than studies examining the ability to use such expressions to regulate interpersonal exchanges. At the neural level, Bachevalier and Loveland (2006) largely agree with the idea that abnormalities in a social brain network are likely to lie at the root of the developmental trajectory of ASD. They particularly emphasize interactions between the orbital-frontal cortex and amygdala as key to understanding the disorder, citing abundant evidence to support the idea that these areas play a critical role in the self regulation of behavior during social-emotional exchanges.

\section{The interpersonal relatedness account}

A view closely related to the behavioral self regulation account is that developed by Hobson $(1993,2002,2012)$ who, like Loveland (2005), emphasizes the need to consider the social-emotional characteristics of ASD within the context of interpersonal processes that encompass perception as well as action. Hobson, however, goes one step further by arguing that people do not simply interact, 
they identify with and share the psychological orientations and attitudes (including emotional) of others. This concept of "interpersonal engagement" may seem difficult to operationalize at first, but observers can reliably determine whether or not two individuals are engaged or not (Hobson and Lee, 1998; García-Pérez et al., 2007). Moreover, very persuasive arguments have been made about the utility of this concept in understanding both typical and atypical forms of interpersonal behavior (Hobson, 1993, 2002, 2012; Hobson and Lee, 1999; Agnetta and Rochat, 2004; Hobson and Meyer, 2005; Meltzoff, 2007; Hobson et al., 2009).

In relation to the social-emotional characterization of ASD, two aspects of Hobson's theory are important to highlight. First, he stresses that the earliest interactions between an infant and her caretakers are emotionally very rich. Caretakers exaggerate their emotional expressiveness and infants react to these with emotional expressions of their own (see Nadel and Muir, 2005 for a collection of reviews). Second, and similar to Loveland (2001, 2005), Hobson (2002) highlights the fact that perception and action are closely interlinked, which is evident soon after birth in the form of "entrainment" whereby infants synchronize their general motility levels with the patterning of adult speech (e.g., Condon, 1979; Kato et al., 1983). Whether innately specified or not, Hobson argues that the synchronized and emotionally patterned quality of early social exchanges forms an ideal and necessary basis for the development of interpersonal engagement (see also Trevarthen's concept of "primary intersubjectivity"; e.g., Trevarthen, 1979). It allows the infant first to discover a connection between her own behaviors and that of others, and through that a connection between behaviors and subjective experiences. In other words, the co-ordinated and affectively rich interactions with others early in life, lays the foundation for the infant to discover that other people are "like me." The argument in relation to ASD is that this capacity to identify with others never fully matures. Although Hobson does not emphasize the neural basis of interpersonal engagement and identification, his account is clearly in line with the notion of a social brain dysfunction and resonates with reports of atypical brain correlates of empathy in ASD (Greimel et al., 2010; Schulte-Rüther et al., 2011; but, see Bird et al., 2010) ${ }^{4}$.

\section{The mentalizing account}

The final explanation to set out before drawing this section to a close is the idea that social-emotional difficulties in ASD are the result of a mentalizing impairment. Mentalizing ${ }^{5}$ refers to the ability to understand, describe, and explain behavior in terms of mental phenomena (e.g., beliefs, desires, intentions, etc. ..) and it is well established that autistic individuals experience difficulties in this domain across a wide range of contexts (Frith, 2001, 2003; see Baron-Cohen, 2001; Boucher, 2012 for reviews). Given that

\footnotetext{
${ }^{4}$ This study showed that atypical empathic brain responses in ASD can be accounted for by co-morbid Alexithymia in this disorder, a point to which I will return in more detail in Section "Reconsidering the Role of Emotion Related Processes in the Development of Autism Spectrum Disorders."

${ }^{5}$ Although the term "Theory of Mind" is often employed to describe this ability, "mentalising" is preferred here to avoid the implication that mental states are understood through a process of theorising or inference - a view that is endorsed by some (e.g., Astington and Gopnik, 1991; Gopnik et al., 1999; Perner, 1991) but not all (e.g., Gordon, 1996; Hobson, 1991, 1993, 2002).
}

emotions are, at least in part, mental phenomena, it is relatively straightforward to see how an impairment in mentalizing would have repercussions for emotion related social behaviors. Nevertheless, it is useful to consider one of the most detailed formulations of such an account more closely.

Baron-Cohen $(1995,2005)$ argues that the ability to mentalize reflects the operation of a Mindreading System that consists of six neuro-cognitive mechanisms - The Intentionality Detector (ID), Eye Direction Detector (EDD), Emotion Detector (TED), Shared Attention Mechanism (SAM), Theory of Mind Mechanism (ToMM), and The Empathizing System (TESS). In typical development, ID, EDD, and TED functionally mature first (between birth and 9 months of age) and endow infants with the ability to comprehend Agent-Object relations in terms of mental processes such as "wanting" something (ID), "seeing" something (EDD), or being "angry" about something (TED). In ASD, the functions of ID, EDD, and TED are thought to be qualitatively preserved although their development may be delayed. Next to mature in typical development (between 9 and 18 months) is SAM, which uses the dyadic representations from ID, EDD, and TED to compute more complex triadic representations of Self-Agent-Object relations. These representations allow infants to understand that the object of their own mental scrutiny may also be the object of another agent's mental scrutiny thus marking the beginnings of joint attention behaviors such as gaze monitoring, protodeclarative pointing, and social referencing. The relative absence of such behaviors is the first reliable clinical marker of ASD (Luyster et al., 2009; see Bruinsma et al., 2004 for a review). Since SAM integrates information from EDD and TED, a developmental failure of SAM should result in particular difficulties to extract mental states including emotions from the eye-region of the face. Both eye-tracking (e.g., Dalton et al., 2005) and behavioral evidence (Baron-Cohen et al., 1997, 2001) lend support to this notion. The final components of the Mindreading System to mature are ToMM (between 18 and 48 months) and TESS (around 14 months), which allow the developing child to understand that mental phenomena do not always represent the world as it truly is (ToMM) and to respond to a subset of mental phenomena - emotions - with appropriate empathy (TESS). Both of these competences are compromised in ASD (see Frith, 2003; Minio-Paluello et al., 2009b; Smith, 2009) although arguments have been levied against this conclusion (e.g., Bowler et al., 2005; Bird et al., 2010).

Similar to the accounts set out earlier, the notion of mentalizing difficulties is fully compatible with the idea that ASD is the result of a social brain dysfunction. Superior temporal and medial prefrontal regions involved in mentalizing constitute a core component of the social brain and Baron-Cohen (1995, 2005) highlights the amygdala as particularly important because of its known sensitivity to social-emotional information (Baron-Cohen et al., 2000; Buchanan et al., 2009). At the cognitive-developmental level, the mentalizing account diverges somewhat from the other three theories set out above, which consider the developmental trajectory of ASD to begin at birth, or soon thereafter. The mentalizing framework, by contrast, considers the failure of SAM to develop at 9-18 months as the starting point of the disorder (see Boucher, 2012 for an excellent discussion of the developmental plausibility of mentalizing accounts). 


\section{SUMMARY}

I hope to have substantiated the three claims that I set out at the beginning of this section. First, that it is well established that autistic individuals experience difficulties in multiple aspects of interpersonal emotional behaviors and processes. Second, that a group of influential explanations of these limitations consider them as a facet or consequence of broader impairments in reciprocal social competences. And third, that it is widely believed that the neural basis of these impairments is a dysfunctional social brain network comprising regions of temporal and frontal cortex as well as sub-cortical limbic and striatal regions. In the next section I will consider the notion of a "social brain" more closely and suggest that its conceptualization in these terms - i.e., as a social brain ignores many of the functions of its components that are critical for far more domain-general emotion related processes. More specifically, I am going to argue that it is premature to assume that only the "social" functions of the autistic brain are compromised.

\section{THE SOCIAL BRAIN AND ITS DOMAIN-GENERAL RESPONSIBILITIES}

Although the neuropathology of ASD is widespread and characterized by a complex developmental trajectory (Akshoomoff et al., 2002; Redcay and Courchesne, 2005; Courchesne et al., 2011), post-mortem, and structural imaging studies highlight the cerebellum, limbic regions (amygdala, hippocampus, insula, and cingulate cortex), temporal cortical areas (particularly the Fusiform Gyrus and Superior Temporal Sulcus), the dorsal striatum (Putamen and Caudate), and portions of the frontal lobes (Inferior, Medial, Middle, and Superior frontal gyri) as key regions of abnormality in the disorder (see Stanfield et al., 2008; Radua et al., 2010; Cauda et al., 2011; Duerden et al., 2012; Nickl-Jockschat et al., 2012 for reviews). At the functional level, the significance of cerebellar abnormalities is only just beginning to be understood (Strick et al., 2009; Schmahmann, 2010; Halloran et al., 2012) but it is consistently demonstrated that abnormalities in the striatum, limbic system (amygdala and cingulate cortex), temporal cortices (superior temporal sulcus and gyrus, fusiform gyrus, and temporal poles), and frontal cortical areas (medial prefrontal, orbitofrontal, and insular cortices) are linked to facets of the socialemotional impairments characterizing ASD (see Di Martino et al., 2009; Minshew and Keller, 2010; Sugranyes et al., 2011; Philip et al., 2010, 2012; Vissers et al., 2012 for reviews; see also Table 2). An abundance of evidence from neurotypical and other clinical populations furthermore supports a role of these same regions in social cognition and behavior (see Kanwisher, 2000; Gallagher and Frith, 2003; Singer, 2006; Adolphs, 2009; Singer and Lamm, 2009). In short, there is little doubt that "social functions" of the autistic brain operate differently.

A developmental perspective adds further weight to the above conclusion, particularly as formulated by social-motivational theories. The seminal work by Johnson and colleagues demonstrates that social brain functions are not entirely innately specified but rather subject to developmental maturation (see Karmiloff-Smith, 1998; Johnson, 2000, 2003, 2011; Johnson et al., 2009). What does seem to be innately specified is a drive to attend particularly to the social environment, or to stimulus patterns that bring about attention biases to the social world. Soon after birth, for instance, babies preferentially orient to stimulus configurations that contain more elements in the top than the bottom half, thus leading to a preference to attend to face stimuli over most non-face stimuli (Johnson et al., 1991; Valenza et al., 1996; Macchi Cassia et al., 2004). Similarly, they prefer to listen to speech sounds over non-speech sounds (Vouloumanos and Werker, 2004). These early attention biases provide the system with the necessary experience to drive the maturation of more and more specialized social-perceptual and social-cognitive functions. Recent studies suggest that 14 month old toddlers who go on to develop ASD demonstrate less of a preference to orient toward social over non-social stimuli (moving children vs. animated geometric patterns) than toddlers who do not develop the disorder (Pierce et al., 2011). Similarly, toddlers who go on to receive a diagnosis demonstrate atypical brain responses to speech stimuli over non-speech stimuli when they are asleep (Eyler et al., 2012). Thus, the existing evidence clearly supports the notion that the developmental trajectory of ASD is characterized by early emerging anomalies in social orienting and the processing of the social environment more generally. Does this mean that such anomalies are the cause of the developmental trajectory of the disorder? Not necessarily. To date, there is no convincing evidence to suggest that autistic infants process specifically "social" information differently. It is equally possible that ASD is characterized by more general atypicalities in orienting to and processing of biologically relevant stimuli of which other people are merely an example. A closer look at the concept of the "social brain" will show that this alternative is not farfetched.

History has taught us that describing a collection of neural structures under an umbrella that implies a domain specific function can introduce unwanted biases in our perceptions of what certain parts of the brain are important for. Thus when Papez (1937) first described the neuroanatomical basis of emotions and MacLean (1949) later introduced the concept of the "visceral brain," they inadvertently diverted attention from the critical role of the hippocampus in memory. In this vein, it is important not to lose sight of the fact that the areas purported to constitute the social brain are involved in a lot more than mediating social behaviors and cognitions (see Adolphs, 2003, 2009). The medial prefrontal cortex, for instance, is not only involved in mentalizing (Gallagher and Frith, 2003) but also more generally in the control of decision making and decision outcome monitoring (Ridderinkhof et al., 2004). The Fusiform Gyrus, though critical for face processing (see Kanwisher, 2000), is also involved in the processing of stimuli relevant to ones' area of expertise (Gauthier et al., 2000). Middle and superior temporal cortices play a role in language processing (Price, 2010) and social perception (Allison et al., 2000) but also in the general representation of abstract meaning (Binder and Desai, 2011). And of most interest in relation to the social-emotional characteristics of ASD, the striatal, and limbic areas of the social brain are critical for mediating the domain-general interactions between emotion and cognition that are of interest in the series of articles comprising this "Special Topic."

The amygdala is well known to be critical for alerting us to biologically relevant events in the environment and to prepare us for action by mobilizing physical as well as cognitive resources. Direct sub-cortical afferents from all sensory modalities allow for the "quick-and-dirty" detection of potentially significant stimuli in 
the environment. Should a rapid response be required, direct efferent connections with hypothalamic and brain-stem nuclei activate arousal systems and "fight-or-flight" responses. A vast network of cortical inputs moderates this sub-cortical system and provides the means for a more controlled response to the environment and a multitude of reciprocal connections with cortical as well as sub-cortical regions allows the amygdala to moderate a wide range of cognitive processes, ranging from perception and attention, through memory and decision making to the most human of capacities - self aware thought (see LeDoux, 1995, 1996; Aggleton, 2000; Lane and Nadel, 2000; Davis and Whalen, 2001; Zald, 2003; Phelps, 2006; Whalen and Phelps, 2009; Dolcos et al., 2011; Ray and Zald, 2012 for a collection of relevant reviews). The dorsal striatum has equally widespread influences. In conjunction with frontal cortical regions and also the amygdala, it is involved in alerting us to reward contingencies in the environment and to facilitates decision making processes to optimize our chances of benefiting from them (e.g., Balleine et al., 2007; Delgado, 2007). There is no doubt that all of these processes are important for navigating the social world successfully - few processes are not! But before we conclude that only the processes relevant to dealing with the social environment are compromised in ASD we must examine these broader functions of the "social brain" carefully and consider how they might contribute to the developmental trajectory of the disorder. Closer scrutiny of the mechanisms that mediate the impact of emotion on cognition, in this context, seems particularly pertinent.

\section{WHAT DO WE KNOW ABOUT THE IMPACT OF EMOTION ON COGNITION IN ASD? \\ AROUSAL RESPONSES IN ASD}

Before we consider how the emotional salience of stimuli impacts on cognitive processes in ASD, it is important to establish to what extent environmental events elicit emotional experiences in this disorder in the first place. Stimulus elicited arousal responses such as changes in cardiac activity, galvanic skin responses (GSRs), or pupil dilation are of considerable interest in this context. Table 3 summarizes studies that have examined such responses in ASD since $1980^{6}$, grouped according to whether arousal was assessed in response to simple sensory stimuli, stimuli varying in emotional significance, stimuli varying on some social dimension (e.g., emotional expression, absence/presence of significant other, gaze direction, etc.), or stress induction procedures. The results are tabulated in terms of whether groups differed with respect to the overall magnitude of arousal responses (Mag.) and/or the extent to which arousal responses differentiated between stimulus categories and/or experimental conditions (Diff.).

Overall, the literature is clearly extremely varied. Importantly, however, there is little evidence to suggest that autistic individuals are either consistently hyper- or hypo-aroused by the social environment. Rogers and Ozonoff (2005) reached a similar conclusion

\footnotetext{
${ }^{6}$ Earlier studies are included in a review of the sensory processing literature by Rogers and Ozonoff (2005) but they are not included here because of the shift in the conceptualisation of ASD as marked by the publication of Wing and Gould (1979). Studies included in Table 3 were identified primarily through cited reference searchers and a Web-of-Knowledge search using the terms arousal and autism.
}

in relation to simple sensory stimuli and it is curious that both the sensory and social environment should yield a mixed pattern of arousal responses in ASD. This varied pattern contrasts the observations of studies examining arousal responses to emotionally salient pictures, words, or narratives where responses to different stimulus categories are sometimes less differentiated but on the whole response magnitudes are relatively preserved. One could formalize this pattern by suggesting that autistic individuals only demonstrate typical arousal responses in relation to stimuli that are relatively unambiguous and invariable with respect to their emotional significance (e.g., spiders, startling noises, profanities, etc.). Responses to more ambiguous stimuli (e.g., arbitrary sensory stimuli or other people), on the other hand, are compromised in a manner that leads to very variable patterns of arousal across contexts. To illustrate, consider the contrast between the emotional significance of profanities and that of the ever-changing behaviors of other people. Profanities, no doubt, acquire their emotional significance within the context of social interactions. Early in development, they are typically encountered in highly emotive situations. A toddler might utter a profanity not knowing what it meant and be scolded, or he may witness a heated argument and be frightened by the aggression on display. Either way, encounters with profanities would fairly reliably be associated with the experience of fear. By contrast, encounters with other people are associated with a whole range of emotional experiences. One moment the adult smiles, the next he scolds and after that he may look puzzled, indifferent, or surprised. Probabilistically, therefore, profanities are associated much more reliably with a particular pattern of emotional experience than encounters with other people (or ambiguous sensory stimuli) and studies of associative learning suggest that this difference is critical in the context of ASD.

\section{LEARNING ABOUT THE EMOTIONAL SIGNIFICANCE OF ENVIRONMENTAL EVENTS}

One of the most important functions of the amygdala is to mediate the associative learning processes through which an organism is able to predict potential danger or reward. The nature of these processes has been studied most extensively through aversive and appetitive conditioning paradigms in which essentially neutral sensory stimuli come to elicit avoidance or approach behaviors because of their predictive validity over inherently harmful or pleasant events (for detailed reviews, see LeDoux, 1995, 1998, 2002; Murray et al., 2009; Öhman, 2009). Four studies have examined aversive conditioning in ASD to date.

\section{Aversive conditioning}

Bernier et al. (2005) examined fear conditioning through a fear potential startle paradigm in which participants were presented with consecutive trials comprising a red square (the Conditioned Stimulus, CS) that co-terminated with an overlapping $50 \mathrm{~ms}$ aversive air-puff to the throat (the unconditioned Stimulus; UCS). Following these acquisition trials, participants' eye-blink startle responses were examined to bursts of white noise that were either preceded by the red square ("threat trials") or not ("safe trials"). The results showed that both autistic and non-autistic individuals exhibited augmented eye-blink startle responses during the threat as compared to the safe trials, suggesting that the red square had 


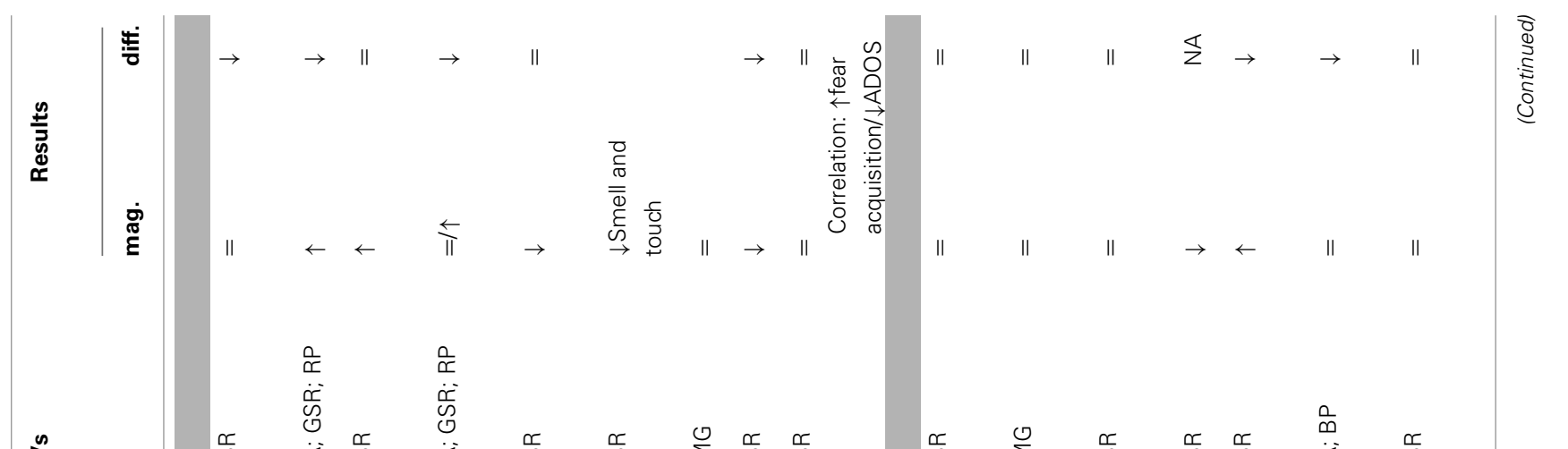

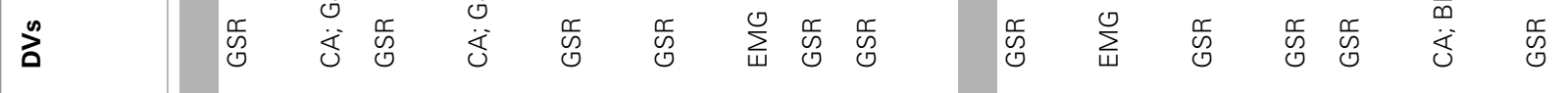
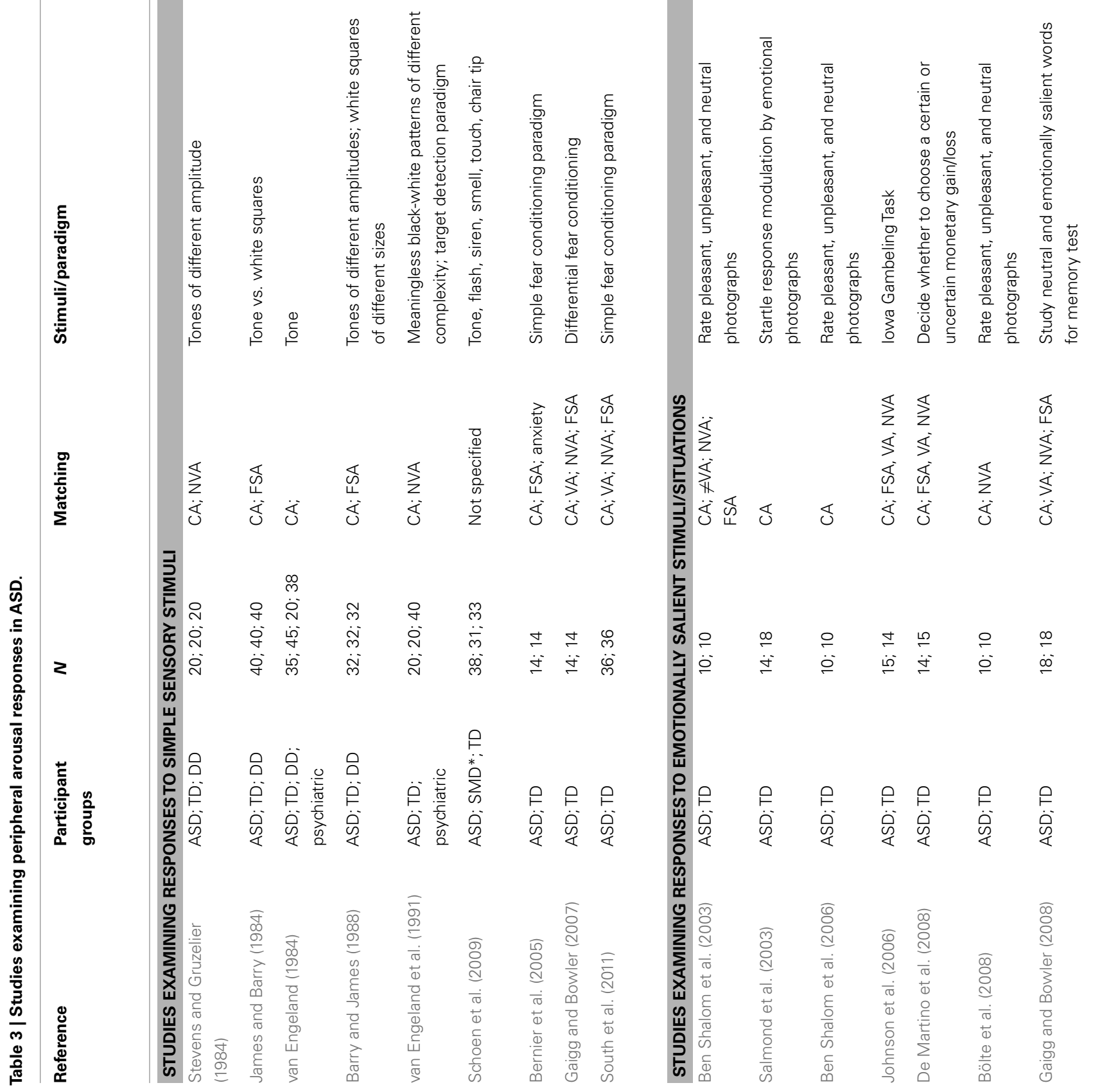

$\begin{array}{ll}\stackrel{+}{m} & m \\ \ddot{N} & \stackrel{m}{m} \\ \ddot{i} & \dot{m}\end{array}$

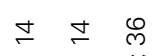

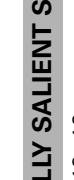

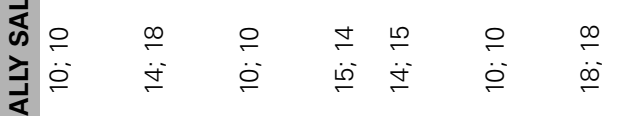

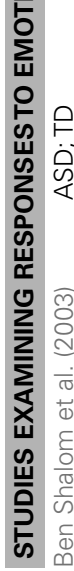

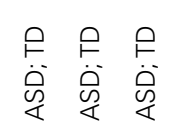
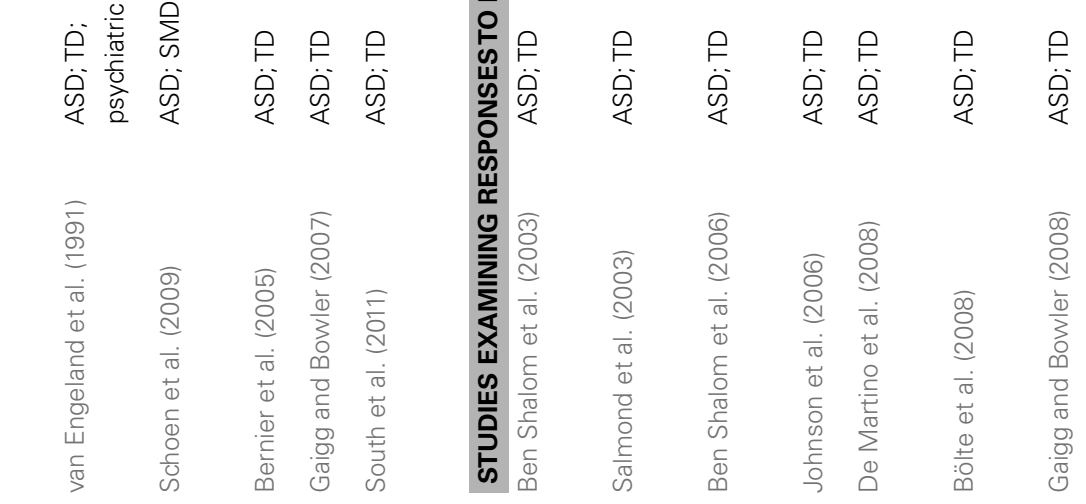


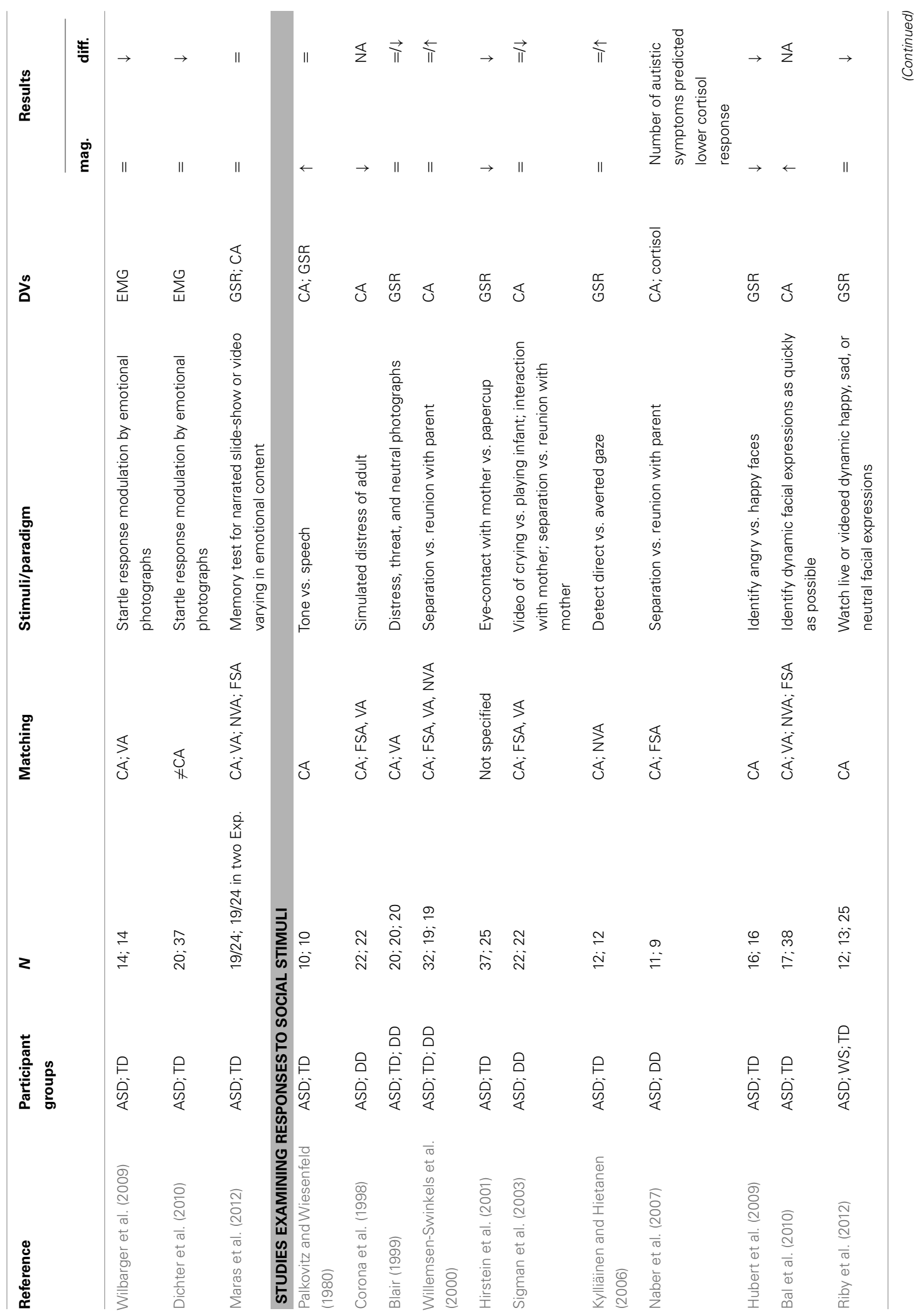




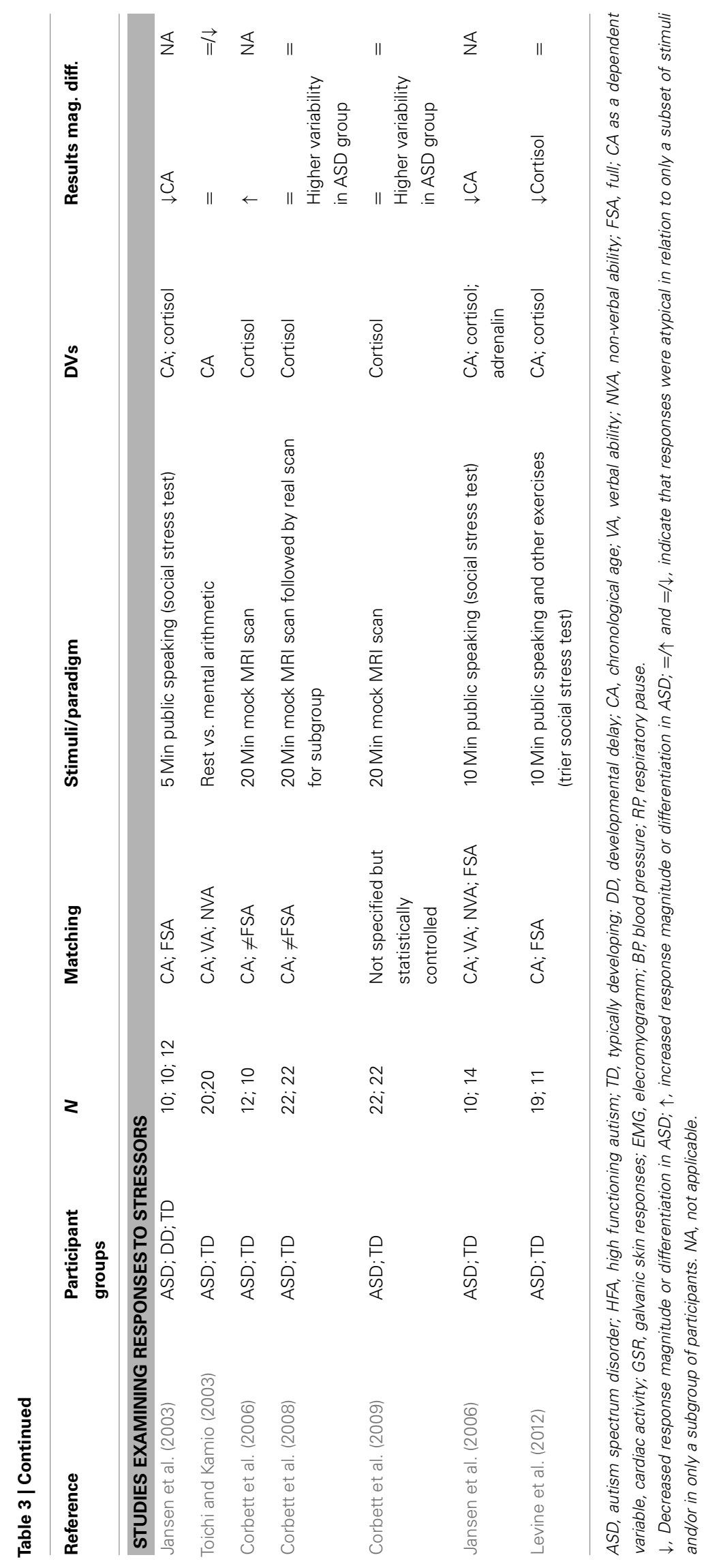


acquired aversive properties for both groups. Gaigg and Bowler (2007) examined fear conditioning in a somewhat more complicated paradigm in which participants saw a random sequence of four colors, of which one (CS+) was paired with a startling foghorn sound (UCS) on a random 6 of its 12 presentations. The remaining colors (CS-) were never paired with the UCS and thus served as "safe" trials. Examination of GSR showed that fear acquisition to the CS+ color was significantly attenuated in autistic as compared to non-autistic individuals.

South et al. (2011) have recently employed a paradigm that sits somewhere in between those of Bernier et al. (2005) and Gaigg and Bowler (2007) in terms of the stimulus contingencies. Similar to Gaigg and Bowler (2007) these authors employed a differential conditioning paradigm involving a CS+ color that was paired with a startling noise UCS during acquisition and a CS- color that was never paired with the UCS. Similar to Bernier et al. (2005), however, South and colleagues always paired the CS+ color with the UCS during the acquisition trials whereas in Gaigg and Bowler (2008) the UCS followed the CS+ on only 50\% of trials. Across three experiments that employed tones, colors, or angry face photographs as conditioned stimuli, South et al. (2011) observed no decrements in fear acquisition in ASD (GSR served as the dependent measure). Importantly, however, the authors did find that the amplitude of acquired fear responses was associated with autism symptom severity such that greater conditioned responses were associated with lower scores on the ADOS Reciprocal Social Interaction scores (i.e., fewer/less severe difficulties in this domain).

In the most recent fear conditioning report in ASD to date, South et al. (in press) employed a reversal paradigm modeled on Schiller et al. (2008). Here participants were presented with a random sequence of two colors of which one (CS+) co-terminated with an aversive puff of air to the throat (UCS) on 33\% of trials. Unannounced, the contingency between color and air-puff reversed such that the previously unpaired $\mathrm{CS}-$ color now coterminated with the UCS whilst the original CS+ color no longer did. The results showed that whilst fear acquisition in the first phase was preserved in ASD, reversal learning was significantly compromised such that autistic individuals were significantly slower to adapt to the new stimulus contingencies.

Importantly, in all four aversive conditioning studies to date, ASD and non-ASD individuals did not differ with respect to their physiological responses to the UCS, which suggests that the emotional salience of these aversive stimuli was similar for both groups. Although further studies are clearly needed to clarify what factors are critical for determining whether or not fear acquisition is preserved in ASD (number of competing stimuli, probability of reinforcement, timing of events, etc.), it seems clear already, that autistic individuals have difficulties adapting to ambiguous stimulus contingencies that would normally allow one to predict the occurrence of biologically relevant events on a probabilistic basis. In other words, ASD seems to be characterized by anomalies in the mechanisms by which emotional salience facilitates associative learning under conditions of uncertainty. Studies of reward contingency learning lend further support to this conclusion.

\section{Reward contingency learning}

Learning to predict when and where to expect rewards is mediated by a complex neural network involving interactions between many parts of the "social brain" including the amygdala and orbitalfrontal cortex (Holland and Gallagher, 2004) and the striatal reward system (Delgado, 2007). Johnson et al. (2006) were the first to examine reward contingency learning in ASD by drawing on a well established decision making paradigm known as the Iowa Gambling Task (IGT; Bechara et al., 1997, 2005). Participants in this task are told to try to make as much money as possible by choosing cards from one of four decks, with each choice yielding a certain monetary gain and loss (e.g., you win $\$ 0.50$ but also lose $\$ 0.75$ ). Two decks yield on average more gains than losses but the distribution of rewards across trials is extremely unpredictable. Johnson et al. (2006) found that autistic individuals were significantly slower to develop choice preferences for the advantageous decks than comparison individuals in this task. Solomon et al. (2011) recently observed similar group differences in a probabilistic learning task in which participants needed to discover which of a pair of symbols had the highest chance of being "correct." For different pairs of symbols, accurate feedback was given on only 80 , 70 , or $60 \%$ of trials and the learning profiles of ASD participants showed that they were less affected by these varying contingencies than comparison individuals (autistic individuals were less likely to demonstrate a "win-stay" pattern of decisions). Finally, ScottVan Zeeland et al. (2010) examined reward contingency learning in ASD in the context of a categorization task that required participants to classify abstract fractal-like images as belonging to either one of two categories. Correct classifications were rewarded either with a certain amount of money or with a smiling female face whilst incorrect classifications yielded either no reward or a sad female face. Similar to Johnson et al. (2006) and Solomon et al. (2011), the reward contingencies were not entirely reliable such that on some blocks of trials inaccurate feedback was given. Again, autistic individuals were significantly worse at the categorization task - so much so that, in both the face and monetary reward conditions, their performance remained at chance whilst that of the comparison group reached over $80 \%$.

Several studies, including that by Scott-Van Zeeland et al. (2010), have examined the neural correlates of reward processing in ASD and the overall consensus in this context is that striatal as well as frontal areas involved in predicting and acting upon rewards in the environment are functionally compromised in this disorder. Importantly, neural abnormalities are evident irrespective of whether the reward comes in the form of a social smile, money, or simple praise (Schmitz et al., 2008; Kohls et al., 2011; Dichter et al., 2012a,b $)^{7}$. Together with the studies of fear conditioning, this evidence strongly suggests that it is not only the "social functions" of the "social brain" that are compromised in ASD. Instead, autistic individuals have difficulties adapting to stimuli that predict biologically relevant events only imperfectly, irrespective of whether these stimuli are other people or not. At the neural level this suggests anomalies in how basic associative learning processes mediated by sub-cortical amygdala systems are modulated by "higher-level" perceptual and conceptual processes that are critical for resolving ambiguities in the environment. Evidence

\footnotetext{
${ }^{7}$ Scott-Van Zeeland et al. (2010) argue that their data supports the idea that particularly "social" rewards are processed atypically in ASD but they do not provide the relevant Reward Condition $\times$ Group analyses, nor do their within condition analyses provide convincing evidence for this conclusion.
} 
from other domains suggests that this may be part of a broader disruption of the interplay between basic emotional response systems (i.e., sub-cortical amygdala circuitry) and cognition.

\section{THE EMOTIONAL MODULATION OF ATTENTION IN ASD}

Besides eliciting arousal responses and facilitating associative learning, the amygdala also plays a critical role in orienting attention toward emotionally significant stimuli (see Vuilleumier, 2005, 2009). To date, only three studies have examined the emotional modulation of attention in ASD in relation to stimuli other than emotionally expressive others. South et al. (2008) employed a visual search task in which participants were asked to determine whether all images in a $3 \times 3$ display were of the same category or not. The arrays either comprised images of spiders, snakes, flowers or mushrooms, or one of these (the "odd-one-out") amongst eight of the others. Both autistic and non-autistic participants demonstrated a well established "threat advantage" effect, whereby the detection of threatening (snakes, spiders) stimuli amongst neutral ones (mushrooms, flowers) was faster than the detection of neutral stimuli amongst threatening ones. Interestingly, autistic individuals have also been shown to demonstrate a typical anger superiority effect in visual search tasks employing face stimuli (Ashwin et al., 2006a; Krysko and Rutherford, 2009; Rosset et al., 2011; but, see Farran et al., 2011) ${ }^{8}$, suggesting that basic threat detection mechanisms may be functionally preserved irrespective of whether the danger comes from the social environment or not. Contrasting these observations from visual search paradigms, Corden et al. (2008b) and Gaigg and Bowler (2009a) observed atypical emotional modulation of the Attentional Blink ( $\mathrm{AB}$ ) phenomenon in ASD. In their studies, participants were presented with rapid sequences of words comprising several distracter items and two target words (T1 and T2) that participants were asked to identify. T1 was always neutral whereas T2 was either neutral or emotionally charged and across trials these two target items were separated by varying temporal delays. Typically, the detection of T2s is significantly attenuated in a period of approximately $100-500 \mathrm{~ms}$ following $\mathrm{T} 1$ but this "AB" is partially overcome when T2 is emotionally charged (e.g., Keil and Ihssen, 2004). Both Corden et al. (2008b) and Gaigg and Bowler (2009a) found that this emotional modulation of the $\mathrm{AB}$ was diminished in ASD.

Further studies are clearly needed to clarify to what extent emotionally salient events capture attention in ASD. In particular it will be important to resolve an apparent paradox between the studies outlined here and the evidence concerning emotional arousal responses in ASD outlined earlier. As noted earlier, arousal responses to stimuli such as emotionally significant pictures or

\footnotetext{
${ }^{8}$ Ashwin et al. (2006a), Rosset et al. (2011), and Krysko and Rutherford (2009) all observed relatively typical anger superiority effects but subtle differences between groups in how the number of distracters affected performance. Ashwin et al. (2006a) suggests that these subtler differences are a reflection of more general face processing difficulties and it is worth noting that atypical effects of distracter numbers have also been noted in attention tasks employing letters as stimuli (Remington et al., 2009). Farran et al. (2011) failed to demonstrate an anger superiority effect, observing an advantage for happy expressions instead - this happy advantage was preserved in ASD. Although the ASD group was somewhat slower than TDs to respond to angry, sad and fearful faces this speed decrement was not significant when comparing autistic individuals to verbal ability matched comparison participants.
}

words appear to be relatively preserved in ASD (Ben Shalom et al., 2006; Gaigg and Bowler, 2008) whereas responses to the social environment including the emotional expressions of others are much more varied (e.g., Hubert et al., 2009 vs. Bal et al., 2010). This appears at odds with the studies outlined in this section, which show that facial expressions of certain emotions and images displaying threats capture attention relatively typically in ASD whereas emotionally charged words do not. Importantly, the mechanisms that regulate peripheral arousal responses operate in parallel to those that regulate attention. The former are mediated primarily by sub-cortical connections between the amygdala's central nucleus and various brain-stem nuclei (e.g., LeDoux, 2002) whereas the latter involve reciprocal connections between the basal/lateral nuclei and sensory processing cortices, and between accessory basal nuclei and the orbital-frontal cortex (see Vuilleumier, 2005, 2009). It is possible, therefore, that sub-cortical amygdala pathways that mediate the expression of physiological arousal responses are relatively preserved in ASD, whilst those that moderate attention through reciprocal connections with cortical areas are compromised. Preserved attention modulation by inherent threat signals such as angry expressions and the sight of a spider could be accommodated within such a view because such stimuli are thought to capture attention by activating relatively simple subcortical response systems. The facilitation of attention in response to emotional words, by contrast, is likely to involve more extensive cortico-amygdala networks that include language processing areas.

\section{Memory for emotionally salient events in ASD}

Another important function of the amygdala is to facilitate declarative memory for emotionally significant events through connections with the hippocampus (see Phelps, 2004; Reisberg and Hertel, 2004; Uttl et al., 2006 for reviews). Six studies have explored this issue in ASD to date. The first was a study by Beversdorf et al. (1998) who presented participants with audio recordings of 10 emotional (e.g., "Carl shot his gun at someone") or 10 neutral (e.g., "Mike is talking on the phone") statements. Following each set participants were allowed unlimited time to write down as many statements as possible and results showed that only nonASD participants recalled the emotional statements better than the neutral ones. Deruelle et al. (2008a) extended these observations to pictorial stimuli using a speeded recognition task. Here participants were asked to study sets of images including six neutral, six positive, and six negative items that were presented for only $150 \mathrm{~ms}$ each. Following every set participants were required to discriminate images they had seen from new ones within $1.5 \mathrm{~s}$ and in line with Beversdorf et al. (1998) only non-ASD participants demonstrated a memory advantage for emotional over neutral images.

South et al. (2008) and Maras et al. (2012) recently failed to demonstrate quantitative anomalies in memory for emotional over neutral material in ASD. In the two experiments by Maras et al. (2012), participants were presented with a neutral or emotionally charged audio-narrated slide-show (Exp. 1) or video clip (Exp. 2) for which memory was subsequently assessed through free recall and forced choice recognition procedures. In both experiments participants who viewed the emotional versions of the 
narratives demonstrated superior memory to those who viewed the neutral narratives and this emotional modulation of memory was similar for ASD and non-ASD participants. In the study by South et al. (2008) participants were asked to study a mixed list of negative (high and low arousal), positive (high and low arousal), and neutral words for a subsequent recognition test and here too autistic individuals demonstrated a preserved memory advantage for emotional words. Importantly, however, ASD participants in this study took significantly longer to respond during the test phase, which, in light of the observations of the speeded recognition test by Deruelle et al. (2008a) outlined above, may indicate that qualitative differences in how emotion modulates memory in ASD may go undetected by some experimental paradigms - reminiscent of studies of facial emotion recognition in this disorder (see The Evidence).

Two studies by Gaigg and Bowler (2008, 2009b) lend some support to the above conclusion. Gaigg and Bowler (2008) also failed to note group differences in memory for emotional over non-emotional words when comparing the free recall of autistic and non-autistic participants on an immediate test of memory. Importantly, however, the authors included categorically related neutral words (items of fruit) in their study and examined forgetting rates over time by testing free recall again after 1 and $24 \mathrm{~h}$ delays. Critically, these features of the experiment revealed that the memory advantage for emotional over non-emotional items on the immediate recall test was commensurate with the advantage for items of fruit over unrelated neutral words, both for ASD and non-ASD participant groups. Over time, however, comparison participants began to demonstrate a specific memory advantage for emotional over non-emotional items whereas autistic individuals did not. In other words, the memory advantage for emotional items observed by South et al. (2008) may simply be a reflection of the effects of semantic factors on memory rather than emotional factors and the narrative structure of the materials used by Maras et al. (2012) may play a similar role. The second study by Gaigg and Bowler (2009b) took a somewhat different approach by focusing on false rather than veridical memory. Participants here were asked to study lists of words comprising orthographic neighbors of critical non-presented items that were either emotionally charged (e.g., tell, fell, sell,. . . for hell) or neutral (e.g., look, took, book,... for hook). On a subsequent recognition test non-autistic participants were very unlikely to falsely endorse emotional items as having been studied but ASD participants made such intrusion errors as often for emotional as non-emotional words.

As is the case for studies of attention, further evidence is needed in order to clarify under what circumstances emotion facilitates memory in ASD typically and under what circumstances memory for emotional material may be hindered. Critical, in this context, is to bear in mind that ASD is generally characterized by a particular pattern of memory strengths and weaknesses (see Boucher and Bowler, 2008; Boucher et al., 2012) that may well contribute to inconsistent observations. On balance, however, it does not appear to be the case that emotional factors exert entirely typical effects on long-term declarative memory in ASD.

\section{THE SUBJECTIVE EXPERIENCES OF FEELINGS IN ASD}

The final issue to consider before drawing this section to a close concerns one of the most elusive questions - how do autistic individuals subjectively experience emotional stimuli? As noted in the preliminary comments, I use the term "feeling" in this review to describe the subjective experiences that arise when the perception of a stimulus or event triggers changes in arousal that, in turn, alter self-conscious thought. Although notions of consciousness and self-awareness continue to be the source of considerable debate, immense progress has been made over the past few years in tracing the neurobiological and psychological origins of subjective experiences. The emerging consensus in this context is that subjective experiences such as feelings critically depend on the convergence of representations of internal body states with representations of the sensory environment in medial frontal cortices and in particular the insula cortex, both of which are under the influence of the amygdala (Damasio, 1994, 1999, 2003; LeDoux, 2002; Critchley et al., 2004; Wiens, 2005; Craig, 2009; Critchley and Nagai, 2012; Seth et al., 2012).

Feelings have recently attracted a lot of attention in ASD because a series of studies have shown that a condition known as Alexithymia is commonly associated with the disorder (Hill et al., 2004; Tani et al., 2004; Berthoz and Hill, 2005; see also Fitzgerald and Bellgrove, 2006; Hill and Berthoz, 2006). Alexithymia is characterized by difficulties in identifying and communicating ones' own emotions and whilst it affects only approximately $10 \%$ of the general population (Mattila et al., 2006), the prevalence in ASD is estimated to be somewhere between 40 and 50\% (Hill et al., 2004; Tani et al., 2004). An appealing explanation for this high co-morbidity is that it is a reflection of mentalizing difficulties. In non-autistic individuals, high levels of Alexithymia are associated with poor mentalizing (e.g., Moriguchi et al., 2006) and since autistic individuals are thought to experience difficulties not only with the understanding of other peoples' minds but also their own minds (see Williams, 2010 for an excellent discussion), high levels of Alexithymia are to be expected. Alternatively, however, high levels of Alexithymia in ASD may be regarded as the result of a disruption in the interplay between emotional arousal and subjective experience. In other words, rather than having difficulties in accessing or reflecting on their feelings, autistic individuals may experience feelings differently because the processes that give rise to them are disrupted. Ben Shalom (2000) was the first to raise this possibility and several studies lend support by showing that physiological arousal responses and subjective ratings of hedonic value in ASD do not co-vary typically (Ben Shalom et al., 2003, 2006; Bölte et al., 2008; Gaigg and Bowler, 2008; Dichter et al., 2010; see also Allen and Heaton, 2010). Moreover, a recent fMRI study has shown that the degree of anterior insula activity during emotional introspection in autistic and non-autistic individuals was moderated by scores on standardized Alexithymia questionnaires whereas activity in the mentalizing system was not (Silani et al., 2008; see also Ebish et al., 2011).

Interestingly, Bird et al. $(2010,2011)$ have recently shown that self-reported levels of Alexithymia account for abnormalities in empathic brain responses, atypical gaze fixations on the eye-region of faces, and poorer facial emotion recognition in ASD (Cook et al., 
in press), which suggests that difficulties in introspecting on own emotions and aspects of the reciprocal social impairments in ASD share a common neuro-cognitive basis. The nature and developmental origin of this common denominator remains unclear. One possibility is that ASD per se is not at all associated with emotion related anomalies but that the difficulties in this domain are fully explained by the high incidence of Alexithymia. Such a view, however, would leave unexplained why Alexithymia should co-occur with ASD far more often than would be expected by chance. A more appealing account, sees Alexithymia in ASD as a reflection of the same aberrant developmental process that also gives rise to varying social and emotion related difficulties. On this view, one might expect the nature of Alexithymia in ASD to differ qualitatively from that observed in non-autistic individuals and future studies are urgently needed to address this issue. In particular, it will be important to seek objective measures of Alexithymia that go beyond the self-report questionnaires currently available and it will be critical to clarify the developmental trajectory of Alexithymia in autistic as well as non-autistic individuals.

\section{RECONSIDERING THE ROLE OF EMOTION RELATED PROCESSES IN THE DEVELOPMENT OF AUTISM SPECTRUM DISORDERS}

I have reviewed evidence demonstrating that ASD is characterized by widespread and pervasive difficulties in social-emotional competences. Autistic individuals often struggle to identify the emotional expressions of others, they frequently do not reciprocate these expressions in a context appropriate manner and they often relate and react to the emotional experiences of others in atypical ways. A group of influential explanations of this facet of the autistic phenotype attribute it to broader abnormalities in social-cognitive processes that find their origin in an early emerging disruption in social-motivation and interpersonal engagement. Put simply the argument is that autistic infants are less motivated (or otherwise hindered) to engage and interact with others, which affords them fewer opportunities to learn from interpersonal experiences and ultimately leads to the clinically defining reciprocal social impairments of the disorder, including anomalies in emotion related interpersonal behaviors. At the neural level, this developmental cascade is thought to reflect abnormalities in the maturation of the "social brain," which comprises frontal and temporal cortical regions as well as parts of the striatum and limbic system (in particular the amygdala).

In the two sections that followed, I raised concerns about the view that emotion related processing anomalies in ASD need to be understood with reference to broader "social" impairments. I pointed out that many components of the "social brain" are critically involved in far more than the mediation of reciprocal social competences. In particular, the limbic and striatal regions encompassed by the social brain are well known to play a critical role in the domain-general emotion related processes that serve to alert an organism to biologically relevant events in the environment so that it may respond to them effectively and learn about contingencies that are likely to predict similar events in the future. In the light of these domain-general functions, greater empirical effort needs to be directed at establishing whether or not the emotion-related difficulties in ASD are merely a facet of social impairments.
In section three, I summarized the available evidence that speaks to this issue to date. I first considered evidence concerning peripheral arousal responses in ASD, which are widely agreed to constitute an important facet of emotional responses to the environment. Although the evidence in this context is very mixed, I noted that there is little support for the notion that autistic individuals respond specifically to their social environment with atypical patterns of arousal. Instead they appear more generally to react differently to objects and events that are either ambiguous (e.g., arbitrary sensory stimuli) or variable (e.g., other people) with respect to their emotional significance, which contrasts their relatively typical responses to clearly defined and invariable emotional signals (e.g., emotionally significant words, pictures, narratives, etc.). After hinting at the possibility that it is the ambiguous and unpredictable nature of certain events in the environment that poses difficulties for autistic individuals, I summarized evidence from aversive conditioning and reward contingency learning paradigms that is consistent with this suggestion. More specifically, I showed that autistic individuals experience difficulties learning about the (emotional) significance of stimuli that predict biologically relevant events or opportunities only imperfectly. They fail to anticipate danger under ambiguous circumstances and do not adopt efficient decision strategies to take advantage of uncertain reward opportunities. When the environment is regular and predictable, by contrast, they are indistinguishable from non-autistic individuals. Importantly, this pattern holds irrespective of whether or not social signals or arbitrary symbols serve as predictors of relevant events. At the neural level, this suggests that relatively basic amygdala functions that are mediated primarily by sub-cortical networks involving sensory efferents from the thalamus and afferents to brain-stem nuclei are preserved in ASD. Functions that rely on the modulation of this sub-cortical system by other cortical or sub-cortical areas, by contrast, appear to be compromised. I concluded section three with an overview of evidence from studies of attention, memory, and the subjective experience of "feelings" that are all consistent with the notion that interactions between "basic" amygdala networks and the rest of the brain may be compromised in ASD, which, incidentally, is also consistent with evidence of widespread abnormalities in interregional connectivity in the autistic brain (Cheng et al., 2010; Schipul et al., 2011; Shukla et al., 2011; Duerden et al., 2012; Vissers et al., 2012). In short, I outlined evidence that is beginning to lead us to question the notion that anomalies in interpersonal emotional behaviors in ASD are best understood with reference to "social" impairments.

\section{IMPLICATIONS FOR DEVELOPMENTAL ACCOUNTS OF ASD}

There is no question that social-motivational accounts of ASD provide an elegant explanation for the impairments in reciprocal social competences that clinically define the disorder. As appealing as such theories are, however, they seem insufficient as explanations for the broader emotion related anomalies I have set out in this review. This may seem relatively unproblematic at first. As Chevallier et al. (2012) point out, failing to explain all facets of the ASD phenotype is "...only problematic if one considers that there ought to be a single explanation behind all the symptoms of ASD... if one agrees that ASD should be studied from a multiple-deficit perspective,... it is important to compare the explanatory power of 
social-motivation vs. social cognition in accounting for social deficits" (p. 236). This argument would be perfectly acceptable, were it not for the evidence set out in this review, which links the social and broader emotion related atypicalities at the neural level. Parsimony, therefore, dictates that we seek a developmental explanation that unifies at least the social and wider emotion related characteristics of ASD and one of the most pressing questions in this context is how best to conceptualize the causal relation between the social-emotional and broader emotion related anomalies set out in this review.

One possibility is that "social" explanations are correct after all and that the broader emotion related impairments reviewed in this paper are a direct consequence of abnormalities in the development of reciprocal social competences. Many of the findings set out in section three are amenable to such a view because it is undoubtedly true that we come to appreciate the emotional significance of objects and events in our environment in the context of rich social interactions (e.g., Bacon et al., 1998; Corona et al., 1998). One may counter this argument by pointing out that it is highly unlikely that atypicalities in the domains of fear conditioning and reward contingency learning would result from abnormalities in reciprocal social development. Cortical areas thought to constitute a critical component of the "social brain" - in particular frontal areas - mature much later in life than the amygdala (e.g., Happaney et al., 2004; Bachevalier and Loveland, 2006), rendering it improbable that the abnormalities that underlie atypical fear conditioning result from atypicalities in the maturation of the "social brain." Even this argument, however, is far from decisive because the highly complex nature of social interactions may well provide the kind of experience that drives not only the specialization of "social" functions of the brain (e.g., Johnson, 2000, 2003, 2011), but also the maturation of inherently non-social functions such as those involved in certain conditioning paradigms. On this account social interactions could be seen to lead to the development of neural circuitry that is intricately tuned to dealing with rapidly changing, ambiguous, and often unpredictable environments. Perturbations in this process as a result of impoverished experiences with the social environment could thus lead to more widespread abnormalities in how an individual adapts to ambiguous and unpredictable situations.

It is clear from the above discussion, that it would be premature to abandon "social" explanations of ASD altogether. It is equally clear, however, that we should no longer simply accept the assumptions on which such explanations are based. We need to begin to take an alternative seriously, one in which impairments in reciprocal social competences are the result of abnormalities in the domain-general processes that typically allow an infant to rapidly learn about the emotional significance of objects and events in its environment. As I have suggested in section three, the associative processes that mediate such learning may be compromised in ASD such that autistic individuals find it difficult to adapt to the (emotional) significance of particularly those stimuli that predict biologically relevant events only imperfectly. Other people happen to be the most ambiguous and unpredictable "stimulus" of all in this respect as they are not only biologically relevant in their own right but they also signal a whole range of biologically relevant events. One moment a smile indicates the imminent arrival of food, the next the playful withdrawal of a preferred toy and the next it is a simple sign of affection that relates to nothing in the external environment at all. And if this were not complex enough, the same face that produces smiles in a dozen different contexts is also the source of a multitude of other, mutually incompatible emotional signals that occasionally occur in the same context as the smile (e.g., a playful frown whilst withdrawing the preferred toy). Making sense of this organized chaos is a computational nightmare that the typically developing brain appears to master in a matter of months. For autistic individuals, however, the unpredictable nature of the social environment appears to remain to a large extent impenetrable.

\section{CONCLUSION AND FUTURE DIRECTIONS}

I have attempted to provide a complete overview of what we currently know about emotion related processes in ASD. On balance, the literature suggests that we may need to reconsider one of the core assumptions that underlies most dominant theories concerning the social-emotional difficulties characterizing the disorder, namely that these difficulties are simply a facet of broader social-motivational or social-cognitive impairments. Should the assumption not withstand empirical scrutiny, we face the difficult task of acknowledging that our conceptualization of the developmental trajectory of ASD as originating in impairments in "social" processes may in fact be false. Fortunately, this prospect is not as daunting as it seems, as there are appealing alternatives on the horizon. In particular, Pellicano and Burr (in press), in a very different context, have recently argued that autistic perception is relatively unbiased by prior experience. More specifically, they argue that whereas typical individuals anticipate, rather than experience the world, autistic individuals perceive the world as it actually is. At a neural level, this phenomenological description of the subjective experiences of autistic individuals is anchored in faulty computational mechanisms that iteratively formulate expectations of what might occur next on the basis of experience. These mechanisms are critical for our survival because they allow us to anticipate biologically relevant events, and in the context of our social environment, they allow us to predict the unpredictable. Pellicano and Burr (in press) suggest that ASD is the result of abnormalities in how current experience updates predictions for the future and this seems a promising idea to pursue in relation to the emotion related experiences of autistic individuals.

\section{ACKNOWLEDGMENTS}

I am grateful to Prof. Dermot Bowler and Dr. Richard Cook for their helpful comments and suggestions on drafts of this manuscript. I would like to thank the British Psychological Society for funding a seminar series on the role of emotion related processes in the development of Autism Spectrum Disorder that provided the impetus for this review. I am indebted to Prof. Peter Hobson who co-organised this seminar series and to all participants who contributed to the thought-provoking discussions about the topic of emotions in the context of ASD. 


\section{REFERENCES}

Adolphs, R. (2003). Is the human amygdala specialized for processing social information? Ann. N. Y. Acad. Sci. 985, 326-340.

Adolphs, R. (2009). The social brain: neural basis of social knowledge. Annu. Rev. Psychol. 60, 693-716.

Adolphs, R., Sears, L., and Piven, J. (2001). Abnormal processing of social information from faces in autism. J. Cogn. Neurosci. 13, 232-240.

Aggleton, J. P. (ed.). (2000). The Amygdala: A Functional Analysis. Oxford: Oxford University Press.

Agnetta, B., and Rochat, P. (2004). Imitative games by 9-, 14-, and 18month-old infants. Infancy 6, 1-36.

Akechi, H., Senju, A., Kikuchi, Y., Tojo, Y., Osanai, H., and Hasegawa, T. (2009). Does gaze direction modulate facial expression processing in children with autism spectrum disorder? Child Dev. 80, 1134-1146.

Akshoomoff, N., Pierce, K., and Courchesne, E. (2002). The neurobiological basis of autism from a developmental perspective. Dev. Psychopathol. 14, 613-634.

Allen, R., and Heaton, P. F. (2010). Autism, music, and the therapeutic potential of music in alexithymia. Music Percept. 27, 251-261.

Allison, T., Puce, A., and McCarthy, G. (2000). Social perception from visual cues: role of the STS region. Trends Cogn. Sci. (Regul. Ed.) 4, 251-291.

American Psychiatric Association. (2000). Diagnostic and Statistical Manual of Mental Disorders (DSM$I V$-TR). Washington, DC: American Psychiatric Association.

Annaz, D., Campbell, R., Coleman, M., Milne, E., and Swettenham, J. (2012). Young children with autism spectrum disorder do not preferentially attend to biological motion. J. Autism Dev. Disord. 42, 401-408.

Ashwin, C., Baron-Cohen, S., Wheelwright, S., O'Riordan, M., and Bullmore, E. T. (2007). Differential activation of the amygdala and the 'social brain' during fearful faceprocessing in Asperger syndrome. Neuropsychologia 45, 2-14.

Ashwin, C., Wheelwright, S., and BaronCohen, S. (2006a). Finding a face in the crowd: testing the anger superiority effect in Asperger syndrome. Brain Cogn. 61, 78-95.

Ashwin, C., Chapman, E., Colle, L., and Baron-Cohen, S. (2006b). Impaired recognition of negative basic emotions in autism: a test of the amygdala theory. Soc. Neurosci. 1, 349-363.
Asperger, H. (1944). Die Autistischen Psychopathen im Kindesalter. Habilitationsschrift. Eur. Arch. Psychiatry Clin. Neurosci. 117, 76-136.

Astington, J. W., and Gopnik, A. (1991). Theoretical explanations of children's understanding of the mind. Br. J. Dev. Psychol. 9, 7-31.

Atkinson, A. P. (2009). Impaired recognition of emotions from body movements is associated with elevated motion coherence thresholds in autism spectrum disorder. $\mathrm{Neu}$ ropsychologia 47, 3023-3029.

Bachevalier, J., and Loveland, K. A. (2006). The orbitofrontal-amygdala circuit and self-regulation of socialemotional behaviour in autism. Neurosci. Biobehav. Rev. 30, 97-117.

Bacon, A. L., Fein, D., Morris, R., Waterhouse, L., and Allen, D. (1998). The responses of autistic children to the distress of others. J. Autism Dev. Disord. 28, 129-142.

Baird, G., Simonoff, E., Pickles, A., Chandler, S., Loucas, T., Meldrum, D., et al. (2006). Prevalence of disorders of the autism spectrum in a population cohort of children in South Thames: the Special Needs and Autism Project (SNAP). Lancet 368, 210-215.

Baker, K. F., Montgomery, A. A., and Abramson, R. (2010). Brief report: perception and lateralization of spoken emotion by youths with high-functioning forms of autism. J. Autism Dev. Disord. 40, 123-129.

Bal, E., Harden, E., Lamb, D., Vaughan, A., Hecke, V., Denver, J. W., et al. (2010). Emotion recognition in children with autism spectrum disorders: relations to eye gaze and autonomic state. J. Autism Dev. Disord. 40, 358-370.

Balleine, B. W., Delgado, M. R., and Hikosaka, O. (2007). The role of the dorsal striatum in reward and decision-making. J. Neurosci. 27, 8161-8165.

Baron-Cohen, S. (1995). Mindblindness: An Essay on Autism and Theory of Mind. Cambridge: MIT Press.

Baron-Cohen, S. (2001). Theory of Mind in normal development and autism. Prisme 34, 147-183.

Baron-Cohen, S. (2005). "The empathizing system: a revision of the 1994 model of the mindreading system," in Origins of the Social Mind, eds B. Ellis and D. Bjorklund (New York: Guildford Press ), 468-490.

Baron-Cohen, S., Leslie, A. M., and Frith, U. (1985). Does the autistic child have a 'theory of mind'? Cognition 21, 37-46.
Baron-Cohen, S., Ring, H. A., Bullmore, E. T., Wheelwright, S., Ashwin, C., and Williams, S. C. (2000). The amygdala theory of autism. Neurosci. Biobehav. Rev. 24 355-364.

Baron-Cohen, S., Spitz, A., and Cross, P. (1993). Do children with autism recognise surprise? A research note. Cogn. Emot. 7, 507-516.

Baron-Cohen, S., and Wheelwright, S. (2004). The empathy quotient: an investigation of adults with Asperger syndrome or high functioning autism, and normal sex differences. J. Autism Dev. Disord. 34, 163-175.

Baron-Cohen, S., Wheelwright, S., Hill, J., Raste, Y., and Plumb, I. (2001). The 'reading the mind in the eyes' test revised version: a study with normal adults, and adults with Asperger syndrome or high-functioning autism. J. Child Psychol. Psychiatry 42, 241-252.

Baron-Cohen, S., Jolliffe, T., Mortimore, C., and Robertson, M. (1997). Another advanced test of theory of mind: evidence from very high functioning adults with autism or Asperger syndrome. J. Child Psychol. Psychiatry 38, 813-822.

Barrett, L. F., Mesquita, B., Ochsner, K. N., and Gross, J. J. (2007). The experience of emotion. Annu. Rev. Psychol. 58, 373-403.

Barry, R. J., and James, A. L. (1988). Coding of stimulus parameters in autistic, retarded, and normal children: evidence for a two-factor theory of autism. Int. J. Psychophysiol. 6, 139-149.

Bastiaansen, J. A., Thioux, M., Nanetti, L., van der Gaag, C., Ketelaars, C., Minderaa, R., et al. (2011). Agerelated increases in inferior frontal gyrus activity and social functioning in autism spectrum disorder. Biol. Psychiatry 69, 832-838.

Beall, P. M., Moody, E. J., McIntosh, D. N., Hepburn, S. L., and Reed, C. L. (2008). Rapid facial reactions to emotional facial expressions in typically developing children and children with autism spectrum disorder. J. Exp. Child Psychol. 101, 206-223.

Bechara, A., Damasio, D., Tranel, D., and Damasio, A. R. (2005). The Iowa Gambling Task and the somatic marker hypothesis: some questions and answers. Trends Cogn. Sci. (Regul. Ed.) 9, 159-162.

Bechara, A., Damasio, H., Tranel, D., and Damasio, A. R. (1997). Deciding advantageously before knowing the advantageous strategy. Science 275, 1293-1295.
Begeer, S., Koot, H. M., Rieffe, C., Terwogt, M. M., and Stegge, H. (2008) Emotional competence in children with autism: diagnostic criteria and empirical evidence. Dev. Rev. 28, 342-369.

Begeer, S., Rieffe, C., Terwogt, M. M., and Stockmann, L. (2006). Attention to facial emotion expressions in children with autism. Autism 10, 37-51.

Ben Shalom, D. (2000). Autism: emotions without feelings. Autism 4, 205-206.

Ben Shalom, D., Mostofsky, S. H., Hazlett, R. L., Goldberg, M. C., McLeod, D. R., and Hoehn-Saric, R. (2003). Intact galvanic skin responses and impaired self-reports in response to emotional pictures in high-functioning autism. Ann. N. Y. Acad. Sci. 985, 501-504.

Ben Shalom, D., Motofsky, S. H., Hazlett, R. L., Goldberg, M. C., Landa, R. J., Faran, Y., et al. (2006). Normal physiological emotions but differences in expression of conscious feelings in children with highfunctioning autism. J. Autism Dev. Disord. 36, 395-400.

Bernier, R., Dawson, G., Panagiotides, H., and Webb, S. (2005). Individuals with autism spectrum disorder show normal responses to a fear potential startle paradigm. J. Autism Dev. Disord. 35, 575-583.

Berthoz, S., and Hill, E. L. (2005). The validity of using self-reports to assess emotion regulation abilities in adults with autism spectrum disorder. Eur. Psychiatry 20, 291-298.

Bertrand, J., Mars, A., Boyle, C., Bove, F., Yeargin-Allsopp, M., and Decoufle, P. (2001). Prevalence of autism in a United States population: the Brick Township, New Jersey, investigation. Pediatrics 108, 1155-1161.

Beversdorf, D. Q., Anderson, J. M., Manning, S. E., Anderson, S. L., Dordgren, R. E., Felopulos, G. J., et al. (1998). The effect of semantic and emotional context on written recall for verbal language in highfunctioning adults with autism spectrum disorder. J. Neurol. Neurosurg. Psychiatr. 65, 685-692.

Bieberich, A. A., and Morgan, S. B. (1998). Brief report: affective expression in children with autism or Down syndrome. J. Autism Dev. Disord. 28, 333-338.

Binder, J. R., and Desai, R. H. (2011). The neurobiology of semantic memory. Trends Cogn. Sci. (Regul. Ed.) 15, 527-536.

Bird, G., Press, C., and Richardson, D. C. (2011). The role of alexithymia in reduced eye-fixation in autism 
spectrum conditions. J. Autism Dev. Disord. 41, 1556-1564.

Bird, G., Silani, G., Brindley, R., White, S., Frith, U., and Singer, T. (2010). Empathic brain responses in insula are modulated by levels of alexithymia but not autism. Brain 133, 1515-1525.

Blair, R. J. R. (1999). Psychophysiological responsiveness to the distress of others in children with autism. Pers. Individ. Dif. 26, 477-485.

Blake, R., Turner, L. M., Smoski, M. J., Pozdol, S. L., and Stone, W. L. (2003). Visual recognition of biological motion is impaired in children with autism. Psychol. Sci. 14, 151-157.

Bölte, S., Feineis-Matthews, S., and Poustka, F. (2008). Brief report: emotional processing in highfunctioning autism - physiological reactivity and affective report. J. Autism Dev. Disord. 38, 776-781.

Bölte, S., and Poustka, F. (2003). The recognition of facial affect in autistic and schizophrenic subjects and their first-degree relatives. Psychol. Med. 33, 907-915.

Boraston, Z., Blakemore, S.-J., Chilvers, R., and Skuse, D. (2007). Impaired sadness recognition is linked to social interaction deficit in autism. Neuropsychologia 45, 1501-1510.

Bormann-Kischkel, C., Vilsmeier, M., and Baude, B. (1995). The development of emotional concepts in autism. J. Child Psychol. Psychiatry 36, 1243-1259.

Boucher, J. (2012). Putting theory of mind in its place: psychological explanations of the socioemotional-communicative impairments in autistic spectrum disorder. Autism 16, 226-246.

Boucher, J., and Bowler, D. (eds). (2008). Memory in Autism: Theory and Evidence. Cambridge: Cambridge University Press.

Boucher, J., and Lewis, V. (1992). Unfamiliar face recognition in relatively able autistic children. J. Child Psychol. Psychiatry 33, 843-859.

Boucher, J., Lewis, V., and Collis, G. (1998). Familiar face and voice matching and recognition in children with autism. J. Child Psychol. Psychiatry 39, 171-181.

Boucher, J., Lewis, V., and Collis, G. M. (2000). Voice processing abilities in children with autism, children with specific language impairments, and young typically developing children. J. Child Psychol. Psychiatry 41, 847-857.

Boucher, J., Mayes, A., and Bigham, S. (2012). Memory in autistic spectrum disorder. Psychol. Bull. 138, 458-496.

Bowler, D. M. (2007). Autism Spectrum Disorders: Psychological Theory and Research. Chichester: Wiley.

Bowler, D. M., Briskman, J., Gurvidi, N., and Fornells-Ambrojo, M. (2005). Understanding the mind or predicting signal-dependent action? Performance of children with and without autism on analogues of the falsebelief task. J. Cogn. Dev. 6, 259-283.

Braverman, M., Fein, D., Lucci, D., and Waterhouse, L. (1989). Affect comprehension in children with pervasive developmental disorder. J. Autism Dev. Disord. 19, 301-316.

Brennand, R., Schepman, A., and Rodway, P. (2011). Vocal emotion perception in pseudo-sentences by secondary-school children with autism spectrum disorder. Res. Autism Spectr. Disord. 5, 1567-1573.

Bruinsma, Y., Koegel, R. L., and Koegel, L. K. (2004). Joint attention and children with autism: a review of the literature. Ment. Retard. Dev. Disabil. Res. Rev. 10, 169-175.

Buchanan, T. W., Tranel, D., and Adolphs, R. (2009). "The human amygdala in social function," in The Human Amygdala, eds P. J. Whalen and E. A. Phelps (New York: The Guilford Press), 289-318.

Buitelaar, J. K., and van der Wees, M. (1997). Are deficits in the decoding of affective cues and in mentalizing abilities independent? J. Autism Dev. Disord. 27, 539-555.

Buitelaar, J. K., van der Wees, M., Swaab-Barneveld, H., and van der Gaag, R. J. (1999). Theory of mind and emotion-recognition functioning in autistic spectrum disorders and in psychiatric control and normal children. Dev. Psychopathol. 11, 39-58.

Cannon, W. B. (1927). The James-Lange theory of emotion: a critical examination and an alternative theory. Am. J. Psychol. 39, 106-124.

Capps, L., Yirmiya, N., and Sigman, M. (1992). Understanding of simple and complex emotions in non-retarded children with autism. J. Child Psychol. Psychiatry 33, 1169-1182.

Castelli, F. (2005). Understanding emotions from standardized facial expressions in autism and normal development. Autism 9, 428-449.

Cauda, F., Geda, E., Sacco, K., D’Agata, F., Duca, S., Geminiani, G., et al. (2011). Grey matter abnormality in autism spectrum disorder: an activation likelihood estimation metaanalysis study. J. Neurol. Neurosurg. Psychiatr. 82, 1304-1314.
Celani, G., Battacchi, M. W., and Arcidiacono, L. (1999). The understanding of the emotional meaning of facial expressions in people with autism. $J$. Autism Dev. Disord. 29, 57-66.

Charman, T., Swettenham, J., BaronCohen, S., Cox, A., Baird, G., and Drew, A. (1997). Infants with autism: an investigation of empathy, pretend play, joint attention and imitation. Dev. Psychol. 33, 781-789.

Cheng, Y., Chou, K.-H., Chen, I.-Y., Fan, Y.-T., Decety, J., and Lin, C.P. (2010). Atypical development of white matter microstructure in adolescents with autism spectrum disorders. Neuroimage 50, 873-882.

Chevallier, C., Kohls, G., Troiani, V., Brodkin, E. S., and Schultz, R. T. (2012). The social motivation theory of autism. Trends Cogn. Sci. (Regul. Ed.) 16, 231-239.

Chevallier, C., Noveck, I., Happé, F., and Wilson, D. (2011). What's in a voice? Prosody as a test case for the theory of mind account of autism. Neuropsychologia 49, 507-517.

Clark, T. F., Winkielman, P., and McIntosh, D. N. (2008). Autism and the extraction of emotion from briefly presented facial expressions: stumbling at the fist step of empathy. Emotion 8, 803-809.

Condon, W. S. (1979). "Neonatal entrainment and enculturationm," in Before Speech: The Beginning of Interpersonal Communication, ed. M. Bullowa (Cambridge: Cambridge University Press), 131-148.

Cook, J., Saygin, A. P., Swain, R., and Blakemore, S.-J. (2009). Reduced sensitivity to minimum-jerk biological motion in autism spectrum conditions. Neuropsychologia 47, 3275-3278.

Cook, R., Brewer, R., Shah, P., and Bird, G. (in press). Alexithymia, not autism, predicts poor recognition of emotional facial expressions. Psychol. Sci.

Corbett, B. A., Carmean, V., Ravizza, S., Wendelken, C., Henry, M. L., Carter, C., et al. (2009). A functional and structural study of emotion and face processing in children with autism. Psychiatry Res. 173, 196-205.

Corbett, B. A., Mendoza, S., Abdullah, M., Wegelin, J. A., and Levine, S. (2006). Cortisol circadian rhythms and response to stress in children with autism. Psychneuroendocrinology 31, 59-68.

Corbett, B. A., Mendoza, S., Wegelin, J. A., Carmean, V., and Levine, S. (2008). Variable cortisol circadian rhythms in children with autism and anticipatory stress. J. Psychiatry Neurosci. 33, 227-234.
Corden, B., Chilvers, R., and Skuse, D. (2008a). Avoidance of emotionally arousing stimuli predicts socialperceptual impairment in Asperger's syndrome. Neuropsychologia 46, 137-147.

Corden, B., Chilvers, R., and Skuse, D. (2008b). Emotional modulation of perception in Asperger's syndrome. J. Autism Dev. Disord. 38, 1072-1080.

Corona, R., Dissanayake, C., Arbelle, S., Wellington, P., and Sigman, M. (1998). Is affect aversive to young children with autism? Behavioural and cardiac responses to experimenter distress. Child Dev. 69, 1494-1502.

Courchesne, E., Campbell, K., and Solso, S. (2011). Brain growth across the life span in autism: age-specific changes in anatomical pathology. Brain Res. 1380, 138-145.

Craig, A. D. (2009). How do you feel now? The anterior insula and human awareness. Nat. Rev. Neurosci. 10, 59-70.

Critchley, H. D., Daly, E. M., Bullmore, E. T., Williams, S. C. R., van Amelsvoort, T., Robertson, D. M., et al. (2000). The functional neuroanatomy of social behaviour: changes in cerebral blood flow when people with autistic disorder process facial expressions. Brain 123 , 2203-2212.

Critchley, H. D., and Nagai, Y. (2012). How emotions are shaped by bodily states. Emot. Rev. 4, 163-168.

Critchley, H. D., Wiens, S., Rotshtein, P., Öhman, A., and Dolan, R. J. (2004). Neural systems supporting interoceptive awareness. Nat. Neurosci. 7, 189-195.

Da Fonseca, D., Santos, A., BastardRosset, D., Rondan, C., Poinso, F., and Deruelle, C. (2009). Can children with autistic spectrum disorders extract emotions out of contextual cues. Res. Autism Spectr. Disord. 3, 50-56.

Dalton, K. M., Nacewicz, B. M., Johnstone, T., Schaefer, H. S., Gernsbacher, M. A., Goldsmith, H. H. et al. (2005). Gaze fixation and the neural circuitry of face processing in autism. Nat. Neurosci. 8, 519-526.

Damasio, A. (1994). Descartes' Error: Emotions, Reason, and the Human Brain. New York: Grosset/Putnam.

Damasio, A. (1999). The Feeling of What Happens: Body, Emotion and the Making of Consciousness. London: Heinemann.

Damasio, A. (2003). Looking for Spinoza: Joy, Sorrow, and the Feeling Brain. New York: Harcourt.

Dapretto, M., Davies, M. S., Pfeifer, J. H., Scott, A. A., Sigman, M., 
Bookheimer, S. Y., et al. (2006). Understanding emotions in others: mirror neuron dysfunction in children with autism spectrum disorders. Nat. Neurosci. 9, 28-30.

Davis, M., and Whalen, P. J. (2001). The amygdala: vigilance and emotion. Mol. Psychiatry 6, 13-34.

Davis, M. S., Dapretto, M., Sigman, M., Sepeta, L., and Bookheimer, S. Y. (2011). Neural bases of gaze and emotion processing in children with autism spectrum disorders. Brain Behav. 1, 1-11.

Davis, S., Bishop, D., Manstead, A. S. R., and Tantam, D. (1994). Face perception in children with autism and Asperger's syndrome. J. Child Psychol. Psychiatry 35, 1033-1057.

Dawson, G., Hill, D., Spencer, A., Galpert, L., and Watson, L. (1990). Affective exchanges between young autistic children and their mothers. J. Abnorm. Child Psychol. 18, 335-345.

Dawson, G., and Lewy, A. (1989). "Arousal, attention and the socioemotional impairments of individuals with autism," in Autism: Nature, Diagnosis, and Treatment, ed. G. Dawson (New York: Guilford), 49-74.

Dawson, G., Webb, S. J., Carver, L., Panagiotides, H., and McPartland, J. (2004). Young children with autism show atypical brain responses to fearful versus neutral facial expressions of emotion. Dev. Sci. 7, 340-359.

Dawson, G., Webb, S. J., and McPartland, J. (2005). Understanding the nature of face processing impairment in autism: insights from behavioural and electrophysiological studies. Dev. Neuropsychol. 27, 403-424.

De Martino, B., Harrison, N. A., Knafo, S., Bird, G., and Dolan, R. J. (2008). Explaining enhanced logical consistency during decision making in autism. J. Neurosci. 28, 10746-10750.

Deeley, Q., Daly, E. M., Surguladze, S., Page, L., Toal, F., Robertson, D., et al. (2007). An event related functional magnetic resonance imaging study of facial emotion processing in Asperger syndrome. Biol. Psychiatry 62, 207-217.

Delgado, M. R. (2007). Reward-related responses in the human striatum. Ann. N. Y. Acad. Sci. 1104, 70-88.

Dennis, M., Lockyer, L., and Lazenby, A. L. (2000). How high-functioning children with autism understand real and deceptive emotion. Autism 4, 370-381.

Deruelle, C., Hubert, B., Santos, A., and Wicker, B. (2008a). Negative emotion does not enhance recall skills in adults with autistic spectrum disorders. Autism Res. 1, 91-96.

Deruelle, C., Rondan, C., SalleCollemiche, X., Bastard-Rosset, D., and Da Fonseca, D. (2008b). Attention to low- and high-spatial frequencies in categorizing facial identities, emotions and gender in children with autism. Brain Cogn. $66,115-123$

Deruelle, C., Rondan, C., Gepner, B., and Tardif, C. (2004). Spatial frequency and face processing in children with autism and Asperger syndrome. J. Autism Dev. Disord. 34 199-210.

Di Martino, A., Ross, K., Uddin, L. Q., Sklar, A. B., Castellanos, F. X., and Milham, M. P. (2009). Functional brain correlates of social and non-social processes in autism spectrum disorders: an activation likelihood estimation meta-analysis. Biol. Psychiatry 65, 63-74.

Dichter, G. S., Benning, S. D., Holtzclaw, T. N., and Bodfish, J. W. (2010). Affective modulation of the startle eyeblink and postauricular reflexes in autism spectrum disorder. J. Autism Dev. Disord. 40, 858-869.

Dichter, G. S., Felder, J. N., Green, S. R., Rittenberg, A. M., Sasson, N. J., and Bodfish, J. W. (2012a). Reward circuitry function in autism spectrum disorders. Soc. Cogn. Affect. Neurosci. 7, 160-172.

Dichter, G. S., Richey, J. A., Rittenberg, A. M., Sabatino, A., and Bodfish, J. W. (2012b). Reward circuitry function in autism during face anticipation and outcomes. J. Autism Dev. Disord. 42, 147-160.

Dissanayake, C., Sigman, M., and Kasari, C. (1996). Long-term stability of individual differences in the emotional responsiveness of children with autism. J. Child Psychol. Psychiatry 37, 461-467.

Dolcos, F., Iordan, A. D., and Dolcos, S. (2011). Neural correlates of emotion-cognition interactions: a review of evidence from brain imaging investigations. J. Cogn. Psychol. 23, 669-694.

Duerden, E. G., Mak-Fan, K. M., Taylor, M. J., and Roberts, S. W. (2012). Regional differences in grey and white matter in children and adults with autism spectrum disorders: an activation likelihood estimate (ALE) meta-analysis. Autism Res. 5, 49-66.

Dyck, M. J., Piek, J. P., Hay, D., Smith, L., and Hallmayer, J. (2006). Are abilities abnormally interdependent in children with autism? J. Clin. Child Adolesc. Psychol. 35, 20-33.
Dziobek, I., Rogers, K., Fleck, S., Bahnemann, M., Heekeren, H. R., Wolf, O. T., et al. (2008). Dissociation of cognitive and emotional empathy in adults with Asperger syndrome using the multifaceted empathy test (MET). J. Autism Dev. Disord. 38, 464-473.

Ebish, S. J. H., Gallese, V., Willems, R. M., Mantini, D., Groen, W. B., Romani, G. L., et al. (2011). Altered intrinsic functional connectivity of anterior and posterior insula regions in high-functioning participants with autism spectrum disorder. Hum. Brain Mapp. 32, 1013-1028.

Ekman, P. (1992). Facial expressions of emotion: new findings, new questions. Psychol. Sci. 3, 34-38.

Evers, K., Noens, I., Steyaert, J., and Wagemans, J. (2011). Combining strengths and weaknesses in visual perception of children with an autism spectrum disorder: perceptual matching of facial expressions. Res. Autism Spectr. Disord. 5, 1327-1342.

Eyler, L. T., Pierce, K., and Courchesne, E. (2012). A failure of left temporal cortex to specialise for language is an early emerging and fundamental property of autism. Brain 135, 949-960.

Farran, E. K., Branson, A., and King, B. J. (2011). Visual search for basic emotional expressions in autism; impaired processing of anger, fear and sadness, but a typical happy face advantage. Res. Autism Spectr. Disord. 5, 455-462.

Fein, D., Lucci, D., Braverman, M., and Waterhouse, L. (1992). Comprehension of affect in context in children with pervasive developmental disorders. J. Child Psychol. Psychiatry 33, 1157-1167.

Fitzgerald, M., and Bellgrove, M. A. (2006). Letter to the editor: the overlap between alexithymia and Asperger's syndrome. J. Autism Dev. Disord. 36, 573-576.

Fogel, A. (1993). Developing Through Relationships: Origins of Communication, Self, and Culture. Hertfordshire: Simon and Schuster.

Frith, U. (2001). Mind blindness and the brain in autism. Neuron 32, 969-979.

Frith, U. (2003). Autism: Explaining the Enigma, 2nd Edn. Oxford: Blackwell Publishing.

Gaigg, S. B., and Bowler, D. M. (2007). Differential fear conditioning in Asperger's syndrome: implications for an amygdala theory of autism. Neuropsychologia 45, 2125-2134.

Gaigg, S. B., and Bowler, D. M. (2008). Free recall and forgetting of emotionally arousing words in autism spectrum disorder. Neuropsychologia 46, 2336-2343.

Gaigg, S. B., and Bowler, D. M. (2009a). Brief report: attenuated emotional suppression of the attentional blink in autism spectrum disorder: another non-social abnormality? J. Autism Dev. Disord. 39, 1211-1217.

Gaigg, S. B., and Bowler, D. M. (2009b). Illusory memories of emotionally charged words in autism spectrum disorder: further evidence for atypical emotion processing outside the social domain. J. Autism Dev. Disord. 39, 1031-1038.

Gallagher, H. L., and Frith, C. D. (2003). Functional imaging of 'theory of mind.' Trends Cogn. Sci. (Regul. Ed.) 7, 77-83.

García-Pérez, R. M., Lee, A., and Hobson, R. P. (2007). On intersubjective engagement in autism: a controlled study of nonverbal aspects of conversation. J. Autism Dev. Disord. 37, 1310-1322.

García-Villamisar, D., Rojahn, J., Zaja, R. H., and Jodra, M. (2010). Facial emotion processing and social adaptation in adults with and without autism spectrum disorder. Res. Autism Spectr. Disord. 4, 756-762.

Gauthier, I., Skudlarsi, P., Gore, J. C., and Anderson, A. W. (2000). Expertise for cars and birds recruits brain areas involved in face recognition. Nat. Neurosci. 3, 191-197.

Gepner, B., Deruelle, C., and Grynfeltt, S. (2001). Motion and emotion: a novel approach to the study of face processing by young autistic children. J. Autism Dev. Disord. 31, 37-45.

Golan, O., Baron-Cohen, S., and Hill, J. (2006). The Cambridge Mindreading (CAM) face-voice battery: testing complex emotion recognition in adults with and without Asperger syndrome. J. Autism Dev. Disord. 36, 169-183.

Gopnik, A., Meltzoff, A. N., and Kuhl, P. K. (1999). The Scientist in the Crib: What Early Learning Tells us About the Mind. New York: Harper Perennial.

Gordon, R. M. (1996). “'Radical' simulationism," in Theories of Theories of Mind, eds P. Carruthers and P. K. Smith (Cambridge: Cambridge University Press), 11-21.

Greimel, E., Schulte-Rüther, M., Kircher, T., Kamp-Becker, I., Remschmidt, H., Fink, G., et al. (2010). Neural mechanisms of empathy in adolescents with autism spectrum disorder and their fathers. Neuroimage 49, 1055-1065. 
Grelotti, D. J., Gauthier, I., and Schultz, R. T. (2002). Social interest and the development of cortical face specialization: what autism teaches us about face processing. Dev. Psychobiol. 40, 213-225.

Grézes, J., Wicker, B., Berthoz, S., and de Gelder, B. (2009). A failure to grasp the affective meaning of actions in autism spectrum disorder subjects. Neuropsychologia 47, 1816-1825.

Gross, T. F. (2002). Perception of human and nonhuman facial age by developmentally disabled children. J. Autism Dev. Disord. 32, 169-179.

Gross, T. F. (2004). The perception of four basic emotions in human and nonhuman faces by children with autism and other developmental disabilities. J. Abnorm. Child Psychol. 32, 469-480.

Gross, T. F. (2005). Global-Local precedence in the perception of facial age and emotional expressions by children with autism and other developmental disabilities. J. Autism Dev. Disord. 35, 773-785.

Grossman, J. B., Klin, A., Carter, A. S., and Volkmar, F. R. (2000). Verbal bias in recognition of facial emotions in children with Asperger's syndrome. J. Child Psychol. Psychiatry 41, 369-379.

Grossman, R. B., Bemis, R. H., Skwerer, D. P., and Tager-Flusberg, H. (2010). Lexical and affective prosody in children with high-functioning autism. J. Speech Lang. Hear. Res. 53, 778-793.

Grossman, R. B., and Tager-Flusberg, H. (2008). Reading faces for information about words and emotions in adolescents with autism. Res. Autism Spectr. Disord. 2, 681-695.

Grossmann, T., and Johnson, M. H. (2007). The development of the social brain in human infancy. Eur. J. Neurosci. 25, 909-919.

Hadjikhani, N., Joseph, R. M., Manoach, D. S., Naik, P., Snyder, J., Dominick, K., et al. (2009). Body expressions of emotion do not trigger fear contagion in autism spectrum disorder. Soc. Cogn. Affect. Neurosci. 4, 70-78.

Hall, G. B. C., Szechtman, H., and Nahmias, C. (2003). Enhanced salience and emotion recognition in autism: a PET study. Am. J. Psychiatry 160, 1439-1441.

Halloran, C. J., Kinsella, G. J., and Storey, E. (2012). The cerebellum and neuropsychological functioning: a critical review. J. Clin. Exp. Neuropsychol. $34,35-56$.

Happaney, K., Zelazo, P. D., and Stuss, D. T. (2004). Development of orbitofrontal function: current themes and future directions. Brain Cogn. 55, 1-10.

Harms, M. B., Martin, A., and Wallace, G. L. (2010). Facial emotion recognition in autism spectrum disorders: a review of behavioural and neuroimaging studies. Neuropsychol. Rev. 20, 290-322.

Heaton, P., Reichenbacher, L., Sauter, D., Allen, R., Scott, S., and Hill, E. (2012). Measuring the effects of alexithymia on perception of emotional vocalisations in autistic spectrum disorder and typical development. Psychol. Med. 4, 1-7.

Heerey, E. A., Keltner, D., and Capps, L. M. (2003). Making sense of selfconscious emotion: linking theory of mind and emotion in children with autism. Emotion 3, 394-400.

Hill, E., Berthoz, S., and Frith, U. (2004). Brief report: cognitive processing of own emotions in individuals with autistic spectrum disorder and in their relatives. J. Autism Dev. Disord. 34, 229-235.

Hill, E. L. (2004). Executive dysfunction in autism. Trends Cogn. Sci. (Regul. Ed.) 8, 26-32.

Hill, E. L., and Berthoz, S. (2006). Response to "letter to the editor: the overlap between alexithymia and Asperger's syndrome," Fitzgerald and Bellgrove, Journal of Autism and Developmental Disorders, 36(4). J. Autism Dev. Disord. 36, 1143-1145.

Hillier, A., and Allison, L. (2002). Understanding embarrassment among those with autism: breaking down the complex emotion of embarrassment among those with autism. J. Autism Dev. Disord. 32, 583-592.

Hirstein, W., Iversen, P., and Ramachandran, V. S. (2001). Autonomic responses of autistic children to people and objects. Proc. R. Soc. Lond. B 268, 1883-1888.

Hobson, J. A., Harris, R., García-Pérez, R., and Hobson, R. P. (2009). Anticipatory concern: a study in autism. Dev. Sci. 12, 249-263.

Hobson, R. P. (1983). The autistic child's recognition of age-related features of people, animals and things. $\mathrm{Br}$. J. Dev. Psychol. 1, 343-352.

Hobson, R. P. (1986a). The autistic child's appraisal of expressions of emotion. J. Child Psychol. Psychiatry 27, 321-342.

Hobson, R. P. (1986b). The autistic child's appraisal of expressions of emotion: a further study. J. Child Psychol. Psychiatry 27, 671-680.

Hobson, R. P. (1991). Against the theory of 'theory of mind.' Br. J. Dev. Psychol. 9, 33-51.
Hobson, R. P. (1993). Autism and the Development of Mind. Hove: Lawrence Erlbaum.

Hobson, R. P. (2002). The Cradle of Thought. London: Pan Macmillan.

Hobson, R. P. (2012). Emotion as personal relatedness. Emot. Rev. 4, 169-175.

Hobson, R. P., and Lee, A. (1998). Hello and goodbye: a study of social engagement in autism. J. Autism Dev. Disord. 28, 117-127.

Hobson, R. P., and Lee, A. (1999). Imitation and identification in autism. J. Child Psychol. Psychiatry 40, 649-659.

Hobson, R. P., and Meyer, J. A. (2005). Foundations for self and other: a study in autism. Dev. Sci. 8, 481-491.

Hobson, R. P., Ouston, J., and Lee, A. (1988a). Emotion recognition in autism: coordinating faces and voices. Psychol. Med. 18, 911-923.

Hobson, R. P., Ouston, J., and Lee, A. (1988b). What's in a face? The case of autism. Br. J. Psychol. 79, 441-453.

Holland, P. C., and Gallagher, M. (2004). Amygdala-frontal interactions and reward expectancy. Curr. Opin. Neurobiol. 14, 148-155.

Homer, M., and Rutherford, M. D. (2008). Individuals with autism can categorize facial expressions. Child Neuropsychol. 14, 419-437.

Howard, M. A., Cowell, P. E., Boucher, J., Broks, P., Mayes, A., Farrant, A., et al. (2000). Convergent neuroanatomical and behavioural evidence of an amygdala hypothesis of autism. Neuroreport 11, 2931-2935.

Hubert, B. E., Wicker, B., Monferadini, E., and Deruelle, C. (2009). Electrodermal reactivity to emotion processing in adults with autistic spectrum disorders. Autism 13, 9-19.

Hubert, B. E., Wicker, B., Moore, D. G., Monfardini, E., Duverger, H., Da Fonseca, D., et al. (2007). Brief report: recognition of emotional and non-emotional biological motion in individuals with autistic spectrum disorder. J. Autism Dev. Disord. 37, 1386-1392.

Hubl, D., Bölte, S., Feineis-Matthews, H., Lanfermann, H., Federspiel, A, Strik, W., et al. (2003). Functional imbalance of visual pathways indicates alternative face processing strategies in autism. Neurology 61, 1232-1237.

Hudenko, W. J., Stone, W., and Bachorowski, J.-A. (2009). Laughter differs in children with autism: an acoustic analysis of laughs produced by children with and without autism. J. Autism Dev. Disord. 39, 1392-1400.
Humphreys, K., Minshew, N., Leonard, G. L., and Behrmann, M. (2007). A fine-grained analysis of facial expression processing in highfunctioning adults with autism. Neuropsychologia 45, 685-695.

Hurdy, K., and Slaughter, V. (2009). Agent familiarity and emotional context influence the everyday empathic responding of young children with autism. Res. Autism Spectr. Disord. 3, 74-85.

James, W. (1890). The Principles of Psychology. New York: Dover Publications.

James, A. L., and Barry, R. J. (1984). Cardiovascular and electrodermal responses to simple stimuli in autistic, retarded and normal children. Int. J. Psychophysiol. 1, 179-193.

Jansen, L. M. C., Gispen-de Wied, C. C., van der Gaag, R.-J., and van Engeland, H. (2003). Differentiation between autism and multiple complex developmental disorder in response to psychosocial stress. $\mathrm{Neu}$ ropsychopharmacology 28, 582-590.

Jansen, L. M. C., Gispen-de Wied, C. C., Wiegant, V. M., Westenberg, H. G. M., Lahuis, B. E., and van Engeland, H. (2006). Autonomic and neuroendocrine responses to a psychosocial stressor in adults with autistic spectrum disorder. J. Autism Dev. Disord. 36, 391-899.

Johnson, M. H. (2000). Functional brain development in humans. Nat. Rev. Neurosci. 2, 476-483.

Johnson, M. H. (2003). Development of human brain functions. Biol. Psychiatry 54, 1312-1316.

Johnson, M. H. (2011). Interactive specialization: a domain-general framework for human functional brain development? Dev. Cogn. Neurosci. 1, 7-21.

Johnson, M. H., Dziurawiec, S., Ellis, H., and Morton, J. (1991). Newborns' preferential tracking of face-like stimuli and its subsequent decline. Cognition 40, 1-19.

Johnson, M. H., Grossmann, T., and Kadosh, K. C. (2009). Mapping functional brain development: building a social brain through interactive specialisation. Dev. Psychol. 45, 151-159.

Johnson, S. A., Yechiam, E., Murphy, R. R., Queller, S., and Stout, J. C. (2006). Motivational processes and autonomic responsivity in Asperger's disorder: evidence from the Iowa Gambling Task. J. Int. Neuropsychol. Soc. 12, 668-676.

Jones, C. R. G., Pickles, A., Falcaro, M., Marsden, A. J. S., Happé, F., Scott, S. K., et al. (2011). A multimodal approach to emotion recognition 
ability in autism spectrum disorders. J. Child Psychol. Psychiatry 52, 275-285.

Joseph, R. M., and Tager-Flusberg, H. (1997). An investigation of attention and affect in children with autism and down syndrome. J. Autism Dev. Disord. 27, 385-396.

Joseph, R. M., and Tanaka, J. (2003). Holistic and part-based face recognition in children with autism. J. Child Psychol. Psychiatry 44, 529-542.

Kamio, Y., Wolf, J., and Fein, D. (2006). Automatic processing of emotional faces in high-functioning pervasive developmental disorders: an affective priming study. J. Autism Dev. Disord. 36, 155-167.

Kanner, L. (1943). Autistic disturbances of affective contact. Nerv. Child 2, 217-205.

Kanwisher, N. (2000). Domain specificity in face perception. Nat. Neurosci. 3, 759-763.

Karmiloff-Smith, A. (1998). Development itself is the key to understanding developmnetal disorders. Trends Cogn. Sci. (Regul. Ed.) 2, 389-398.

Kasari, C., Sigman, M., Mundy, P., and Yirmiya, N. (1990). Affective sharing in the context of joint attention interactions of normal, autistic, and mentally retarded children. J. Autism Dev. Disord. 20, 87-100.

Kasari, C., Sigman, M. D., Baumgartner, P., and Stipek, D. J. (1993). Pride and mastery in children with auism. J. Child Psychol. Psychiatry 34, 353-362.

Kato, T., Takahashi, E., Sawada, K., Kobayashi, N., Watanabe, T., and Ishii, T. (1983). A computer analysis of infant movements synchronized with adult speech. Pediatr. Res. 17, 625-628.

Kätsyri, J., Saalasti, S., Tiippana, K., von Wendt, L., and Sams, M. (2008). Impaired recognition of facial emotions from low-spatial frequencies in Asperger syndrome. Neuropsychologia 46, 1888-1897.

Keil, A., and Ihssen, N. (2004). Identification facilitation for emotionally arousing verbs during the attentional blink. Emotion 4, 23-35.

Kleinhans, N. M., Richards, T., Weaver, K., Johnson, L. C., Greenson, J., Dawson, G., et al. (2010). Association between amygdala response to emotional faces and social anxiety in autism spectrum disorders. Neuropsychologia 48, 3665-3670.

Klin, A., Jones, W., Schultz, R. T., Volkmar, F. R., and Cohen, D. J. (2002). Visual fixation patterns during viewing of naturalistic social situations as predictors of social competence in individuals with autism. Arch. Gen. Psychiatry 59, 809-816.

Kohls, G., Peltzer, J., Schulte-Rüther, M., Kamp-Becker, I., Remschmidt, H., Herpertz-Dahlmann, B., et al. (2011). Atypical brain responses to reward cues in autism as revealed by event-related potentials. J. Autism Dev. Disord. 41, 1523-1533.

Koldewyn, K., Whitney, D., and Rivera, S. M. (2011). Neural correlates of coherent and biological motion perception in autism. Dev. Sci. 14, 1075-1088.

Korpilahti, P., Jansson-Verkasalo, E., Mattila, M.-L., Kuusikko, S., Suominen, K., Rytky, S., et al. (2007). Processing of affective speech prosody is impaired in Asperger syndrome. J. Autism Dev. Disord. 37, 1539-1549.

Krebs, J. F., Biswas, A., Pascalis, O., Kamp-Becker, I., Remschmidt, H., and Schwarzer, G. (2011). Face processing in children with autism spectrum disorder: independent or interactive processing of facial identity and facial expression? J. Autism Dev. Disord. 41, 796-804.

Krysko, K. M., and Rutherford, M. D. (2009). A threat-detection advantage in those with autism spectrum disorders. Brain Cogn. 69, 472-480.

Kujala, T., Lepistö, T., Nieminen-von Wendt, T., Näätänen, P., and Näätänen, R. (2005). Neurophysiological evidence for cortical discrimination impairment of prosody in Asperger syndrome. Neurosci. Lett. $383,260-265$.

Kuusikko, S., Haapsamo, H., JanssonVerkasalo, E., Hurtig, T., Mattila, M.L., Ebeling, H., et al. (2009). Emotion recognition in children and adolescents with Autism spectrum disorders. J. Autism Dev. Disord. 39, 939-945.

Kylliäinen, A., and Hietanen, J. K. (2006). Skin conductance responses to another person's gaze in children with autism. J. Autism Dev. Disord. 36, 517-525.

Lane, R. D. (2006). Theory of emotional awareness and brain processing of emotion. Int. Congr. Ser. 1287, 116-121.

Lane, R. D., and Nadel, L. (eds). (2000). Cognitive Neuroscience of Emotion. Oxford: Oxford University Press.

Law Smith, M. J., Montagne, B., Perrett, D. I., Gill, M., and Gallagher, L. (2010). Detecting subtle facial emotion recognition deficits in highfunctioning autism using dynamic stimuli of varying intensities. $\mathrm{Neu}$ ropsychologia 48, 2777-2781.

Lazarus, R. S. (1984). On the primacy of cognition. Am. Psychol. 39, 124-129.
LeDoux, J. (1996). The Emotional Brain. New York: Simon and Schuster.

LeDoux, J. E. (1995). Emotion: clues from the brain. Annu. Rev. Psychol. 46, 209-235.

LeDoux, J. E. (1998). The neural circuits underlying anxiety and fear. Biol. Psychiatry 44, 1229-1238.

LeDoux, J. E. (2002). Synaptic Self: How Our Brains Become Who We Are. New York: Viking.

Leslie, A. M., and Frith, U. (1990). Prospects for cognitive neuropsychology of autism: Hobson's choice. Psychol. Rev. 97, 122-131.

Levenson, R. W. (1992). Autonomic nervous system differences among emotions. Psychol. Sci. 3, 23-38.

Levine, T. P., Sheinkopf, S. J. Pescosolido, M., Rodino, A., Elia, G., and Lester, B. (2012). Physiologic arousal to social stress in children with autism spectrum disorders: a pilot study. Res. Autism Spectr. Disord. 6, 177-183.

Lindner, J. L., and Rosén, L. A. (2006). Decoding of emotion through facial expression, prosody and verbal content in children and adolescents with Asperger's syndrome. J. Autism Dev. Disord. 36, 769-777.

Lombardo, M. V., Barnes, J. L., Wheelwright, S. J., and BaronCohen, S. (2007). Self-referential cognition and empathy in autism. PLoS ONE 2:e883. doi:10.1371/journal.pone. 0000883

Lord, C., Rutter, M., and Couteur, A. L. (1994). Autism diagnostic interview-revised: a revised version of a diagnostic interview for caregivers of individuals with possible pervasive developmental disorders. J. Autism Dev. Disord. 24, 659-685.

Lord, C., Rutter, M., Goode, S., Heemsbergen, J., Jordan, H., Mawhood, L., et al. (1989). Autism diagnostic observation schedule: a standardized observation of communicative and social behaviour. J. Autism Dev. Disord. 19, 185-212.

Losh, M., and Capps, L. (2003). Narrative ability in high-functioning children with autism or Asperger's syndrome. J. Autism Dev. Disord. 33 239-251.

Loveland, K. A. (2001). "Toward an ecological theory of autism," in The Development of Autism: Perspectives from Theory and Research, eds J. A. Burack, T. Charman, N. Yirmiya, and P. R. Zelazo (Mahwah, NJ: Lawrence Erlbaum Associates), 17-37.

Loveland, K. A. (2005). "Socialemotional impairment and self-regulation in autism spectrum disorders," in Emotional Development, eds J. Nadel and D.
Muir (Oxford: Oxford University Press), 365-382.

Loveland, K. A., and Tunali, B. (1991). Social scripts for conversational interactions in autism and down syndrome. J. Autism Dev. Disord. 21, 177-186.

Loveland, K. A., Tunali-Kotoski, B., Chen, R., Brelsford, K. A., Ortegon, J., and Pearson, D. A. (1995). Intermodal perception of affect in persons with autism or Down syndrome. Dev. Psychopathol. 7, 409-418.

Loveland, K. A., Tunali-Kotoski, B., Chen, Y. R., Ortegon, J., Pearson, D. A., Brelsford, K. A., et al. (1997). Emotion recognition in autism: verbal and nonverbal information. Dev. Psychopathol. 9, 579-593.

Luyster, R., Gotham, K., Guthrie, W., Coffing, M., Petrak, R., Pierce, K., et al. (2009). The autism diagnostic observation schedule - toddler module: a new module of a standardised diagnostic measure for autism spectrum disorders. J. Autism Dev. Disord. 39, 1305-1320.

Macchi Cassia, V., Turati, C., and Simion, F. (2004). Can a nonspecific bias toward top-heavy patterns explain newborn's face preference? Psychol. Sci. 15, 379-383.

Macdonald, H., Rutter, M., Howlin, P., Rios, P., Le Conteur, A., Evered, C., et al. (1989). Recognition and expression of emotional cues by autistic and normal adults. J. Child Psychol. Psychiatry 30, 865-877.

MacLean, P. D. (1949). Psychosomatic disease and the "visceral brain": recent developments bearing on the Papez theory of emotion. Psychosom. Med. 11, 338-353.

Magnée, M. J. C. M., de Gelder, B., van Engeland, H., and Kemner, C. (2007). Facial electromyographic responses to emotional information from faces and voices in individuals with pervasive developmental disorders. J. Child Psychol. Psychiatry 11, 1122-1130.

Maras, K. L., Gaigg, S. B., and Bowler, D. M. (2012). Memory for emotionally arousing events over time in autism spectrum disorder. Emotion 12, 1118-1128.

Mathewson, K. J., Drmic, I. E., Jetha, M. K., Bryson, S. E., Goldberg, J. O., Hall, G. B., et al. (2011). Behavioural and cardiac responses to emotional stroop in adults with autism spectrum disorders: influence of medication. Autism Res. 4, 98-108.

Mattila, A. K., Salminen, J. K., Nummi, T., and Joukamaa, M. (2006). Age is 
strongly associated with alexithymia in the general population. J. Psychosom. Res. 61, 629-635.

Mazefsky, C. A., and Oswald, D. P. (2007). Emotion perception in Asperger's syndrome and highfunctioning autism: the importance of diagnostic criteria and cue intensity. J. Autism Dev. Disord. 37, 1086-1095.

McCann, J., Peppé, S., Gibbon, F. E., O'Hare, A., and Rutherford, M. (2007). Prosody and its relationship to language in school-aged children with high-functioning autism. Int. J. Lang. Commun. Disord. 42, 682-702.

McIntosh, D. M., Reichmann-Decker, A., Winkielman, P., and Wilbarger, J. L. (2006). When the social mirror breaks: deficits in automatic, but not voluntary, mimicry of emotional facial expressions in autism. Dev. Sci. 9, 295-302.

Meltzoff, A. N. (2007). The 'like me' framework for recognizing and becoming an intentional agent. Acta Psychol. (Amst.) 124, 26-43.

Merleau-Ponty, M. (1964). The Primacy of Perception. Chicago: Northwestern University Press.

Minio-Paluello, I., Baron-Cohen, S., Avenanti, A., Walsh, V., and Aglioti, M. (2009a). Absence of embodied empathy during pain observation in Asperger syndrome. Biol. Psychiatry 65, 55-62.

Minio-Paluello, I., Lombardo, M. V., Chakrabarti, B., Wheelwright, S., and Baron-Cohen, S. (2009b). Response to Smith's letter to the editor 'emotional empathy in autism spectrum conditions: weak, intact or heightened'? J. Autism Dev. Disord. 39, 1749-1754.

Minshew, N. J., and Keller, T. A. (2010). The nature of brain dysfunction in autism: functional brain imaging studies. Curr. Opin. Neurol. 23, 124-130.

Miyahara, M., Bray, A., Tsujii, M., Chikako, F., and Sugiyama, T. (2007). Reaction time of facial affect recognition in Asperger's disorder for cartoon and real, static and moving faces. Child Psychiatry Hum. Dev. 38, 121-134.

Monk, C. S., Weng, S.-J., Wiggins, J. L., Kurapati, N., Louro, H. M. C., Carrasco, M., et al. (2010). Neural circuitry of emotional face processing in autism spectrum disorders. J. Psychiatry Neurosci. 35, 105-114.

Moore, D. G., Hobson, R. P., and Lee, A. (1997). Components of person perception: an investigation with autistic, non-autistic retarded and typically developing children and adolescents. Br. J. Dev. Psychol. 15, 401-423.

Moriguchi, Y., Ohnishi, T., Lane, R. D., Maeda, M., Mori, T., Nemoto, K., et al. (2006). Impaired self-awareness and theory of mind: an fMRI study of mentalising in alexithymia. Neuroimage 32, 1472-1482.

Mottron, L., and Burack, J. (2001). "Enhanced perceptual functioning in the development of autism," in Development and Autism: Perspectives from Theory and Research, eds J. Burack, A. Charman, N. Yirmiya, and P. R. Zelazo (New Jersey: Lawrence Erlbaum Associates), 131-148.

Mottron, L., Dawson, M., Soulières, I., Hubert, B., and Burack, J. (2006). Enhanced perceptual functioning in autism: an update, and eight principles of autistic perception. J. Autism Dev. Disord. 36, 27-43.

Mundy, P., and Sigman, M. (1989). "Specifying the nature of the social impairment in autism," in Autism: Nature Diagnosis and Treatment, ed. G. Dawson (New York: The Guildford Press), 3-21.

Murray, E.A., Izquierdo, A., and Malkova, L. (2009). “Amygdala function in positive reinforcement: contributions from studies of nonhuman primates," in The Human Amygdala, eds P. J. Whalen and E. A. Phelps (New York: The Guilford Press), 82-104.

Naber, F. B. A., Swinkels, S. H. N., Buitelaar, J. K., BakermansKranenburg, M. J., van Ijzendoorn, M. H., Dietz, C., et al. (2007). Attachment in toddlers with autism and other developmental disorders. J. Autism Dev. Disord. 37, 1123-1138.

Nadel, J., and Muir, D. (eds). (2005). Emotional Development. Oxford: Oxford University Press.

Nickl-Jockschat, T., Habel, U., Maria, M. T., Manning, J., Laird, A. R., Fox, P. T., et al. (2012). Brain structure anomalies in autism spectrum disorder: a meta-analysis of VBM studies using anatomic likelihood estimation. Hum. Brain Mapp. 33, 1470-1489.

Oagi, M., Matsumoto, H., Suzuki, K., Ozawa, F., Fukuda, R., Uchiyama, I., et al. (2003). fMRI study of recognition of facial expressions in high-functioning autistic patients. Neuroreport 14, 559-563.

Oberman, L. M., Winkielman, P., and Ramachandran, V. S. (2009). Slow echo: facial EMG evidence for the delay of spontaneous, but not voluntary, emotional mimicry in children with autism spectrum disorders. Dev. Sci. 12, 510-520.

O'Connor, K. (2007). Brief report: impaired identification of discrepancies between expressive faces and voices in adults with Asperger's syndrome. J. Autism Dev. Disord. 37, 2008-2013.

O'Connor, K., Hamm, J. P., and Kirk, I. J. (2005). The neurophysiological correlates of face processing in adults and children with Asperger's syndrome. Brain Cogn. 59, 82-95.

Öhman, A. (2009). "Human fear conditioning in the amygdala," in The Human Amygdala, eds P. J. Whalen and E. A. Phelps (New York: The Guilford Press), 118-154.

Ozonoff, S., Pennington, B. F., and Rogers, S. J. (1990). Are there emotion perception deficits in young autistic children? J. Child Psychol Psychiatry 31, 343-361.

Ozonoff, S., Pennington, B. F., and Rogers, S. J. (1991a). Executive function deficits in high-functioning autistic individuals: relationship to theory of mind. J. Child Psychol. Psychiatry 32, 1081-1105.

Ozonoff, S., Rogers, S. J., and Pennington, B. F. (1991b). Asperger's syndrome: evidence of an empirical distinction from high-functioning autism. J. Child Psychol. Psychiatry 32, 1107-1122.

Palkovitz, R. J., and Wiesenfeld, A. R. (1980). Differential autonomic responses of autistic and normal children. J. Autism Dev. Disord. 10, 347-360.

Papez, J. W. (1937). A proposed mechanism of emotion. Arch. Neurol. Psychiatry 38, 725-743.

Pellicano, E., and Burr, D. (in press). When the world becomes too real: a Bayesian explanation of autistic perception. Trends Cogn. Sci. (Regul. Ed.) 16, 504-510.

Pellicano, E., Ne'eman, A., and Stears, M. (2011). Engaging, not excluding: a response to Walsh et al. Nat. Rev. Neurosci. 12, 769.

Pelphrey, K. A., Morris, J. P., McCarthy, G., and LaBar, K. S. (2007). Perception of dynamic changes in facial affect and identity in autism. Soc. Cogn. Affect. Neurosci. 2, 140-149.

Pelphrey, K. A., Sasson, N. J., Reznick, J. S., Paul, G., Goldman, B. D., and Piven, J. (2002). Visual scanning of faces in autism. J. Autism Dev. Disord. 32, 4, 249-261.

Peppé, S., McCann, J., Gibbon, F., O'Hare, A., and Rutherford, M. (2007). Receptive and expressive prosodic ability in children with high-funtioning autism. J. Speech Lang. Hear. Res. 50, 1015-1028.
Perner, J. (1991). Understanding the Representational Mind. Cambridge, MA: MIT Press.

Phelps, E. A. (2004). Human emotion and memory: interactions of the amygdala and hippocampal complex. Curr. Opin. Neurobiol. 14, 198-202.

Phelps, E. A. (2006). Emotion and cognition: insights from studies of the human amygdala. Annu. Rev. Psychol. 24, 27-53.

Philip, R. C. M., Dauvermann, M. R., Whalley, H. C., Baynham, K., Lawrie, S. M., and Stanfield, A. C. (2012). A systematic review and meta-analysis of the fMRI investigation of autism spectrum disorders. Neurosci. Biobehav. Rev. 36, 901-942.

Philip, R. C. M., Whalley, H. C., Stanfield, A. C., Sprengelmeyer, R., Santos, I. M., Young, A. W., et al. (2010). Deficits in facial, body movement and vocal emotional processing in autism spectrum disorders. Psychol. Med. 40, 1919-1929.

Pierce, K., Conant, D., Hazin, R., Stoner, R., and Desmond, J. (2011). Preference for geometric patterns early in life as a risk factor for autism. Arch. Gen. Psychiatry 68, 101-109.

Piggot, J., Kwon, H., Mobbs, D., Blasey, C., Lotspeich, L., Menon V., et al. (2004). Emotional attribution in high-functioning individuals with autistic spectrum disorder: a functional imaging study. J. Am. Acad. Child Adolesc. Psychiatry 43, 473-480.

Price, C. J. (2010). The anatomy of language: a review of $100 \mathrm{fMRI}$ studies published in 2009. Ann. N. Y. Acad. Sci. 1191, 62-88.

Prior, M., Dahlstrom, B., and Squires, T.L. (1990). Autistic children's knowledge of thinking and feeling states in other people. J. Child Psychol. Psychiatry 31, 587-601.

Prior, M., Eisenmajer, R., Leekam, S. R., Wing, L., Gould, J., and Ong, B. (1998). Are there subgroups within the autistic spectrum? A cluster analysis of a group of children with autistic spectrum disorders. J. Child Psychol. Psychiatry 39, 893-902.

Radua, J., Via, E., Catani, M., and Mataix-Cols, D. (2010). Voxelbased meta-analysis of regional white-matter volume differences in autism spectrum disorder versus healthy controls. Psychol. Med. 41, 1539-1550.

Ray, R. D., and Zald, D. H. (2012). Anatomical insights into the interaction of emotion and cognition in the prefrontal cortex. Neurosci. Biobehav. Rev. 36, 479-501. 
Redcay, E., and Courchesne, E. (2005). When is the brain enlarged in autism? A meta-analysis of all brain size reports. Biol. Psychiatry 58, 1-9.

Reisberg, D., and Hertel, P. (eds). (2004). Memory and Emotion. Oxford: Oxford University Press.

Reisenzein, R. (1983). The Schachter theory of emotion: two decades later. Psychol. Bull. 94, 239-264.

Remington, A., Swettenham, J., Campbell, R., and Coleman, M. (2009). Selective attention and perceptual load in autism spectrum disorder. Psychol. Sci. 29, 1388-1393.

Riby, D. M., Whittle, L., and DohertySneddon, G. (2012). Physiological reactivity to faces via live and videomediated communication in typical and atypical development. J. Clin. Exp. Neuropsychol. 34, 385-395.

Ridderinkhof, K. R., Ullsperger, M., Crone, E. A., and Nieuwenhuis, S. (2004). The role of the medial frontal cortex in cognitive control. Science 306, 443-447.

Robel, L., Ennouri, K., Piana, H., VaivreDouret, L., Perier, A. l., Flament, M. F., and Mouren-Siméoni, M.C. (2004). Discrimination of face identities and expressions in children with autism: same or different? Eur. Child Adolesc. Psychiatry 13, 227-233.

Robins, D. L., Fein, D., Barton, M. L., and Green, J. A. (2001). The modified checklist for autism in toddlers: an initial study investigating the early detection of autism and pervasive developmental disorders. J. Autism Dev. Disord. 31, 131-144.

Rogers, K., Dziobek, I., Hassenstab, J., Wolf, O. T., and Convit, A. (2007). Who cares? Revisiting empathy in asperger syndrome. J. Autism Dev. Disord. 37, 709-715.

Rogers, S. J., and Ozonoff, S. (2005). Annotation: what do we know about sensory dysfunction in autism? A critical review of the empirical evidence. J. Child Psychol. Psychiatry 46, 1255-1268.

Rosset, D., Santos, A., Da Fonseca, D., Rondan, C., Poinso, F., and Deruelle, C. (2011). More than just another face in the crowd: evidence for an angry superiority effect in children with and without autism. Res. Autism Spectr. Disord. 5, 949-956.

Rosset, D. B., Rondan, C., Da Fonseca, D., Santos, A., Assouline, B., and Deruelle, C. (2008). Typical emotion processing for cartoon but not for real faces in children with autistic spectrum disorders. J. Autism Dev. Disord. 38, 919-925.

Rump, K. M., Giovannelli, J. L., Minshew, N. J., and Strauss, M. S. (2009).
The development of emotion recognition in individuals with autism. Child Dev. 80, 1434-1447.

Russell, J. A. (2003). Core affect and the psychological construction of emotion. Psychol. Rev. 110, 145-172.

Rutherford, M. D., and McIntosh, D. N. (2007). Rules versus prototype matching: strategies of perception of emotional facial expressions in the autism spectrum. J. Autism Dev. Disord. 37, 187-196.

Rutherford, M. D., Troubridge, E. K., and Walsh, J. (2012). Visual afterimages of emotional faces in high functioning autism. J. Autism Dev. Disord. 42, 221-229.

Salmond, C. H., de Haan, M., Friston, K. J., Gadian, D. G., and Vargha-Khadem, F. (2003). Investigating individual differences in brain abnormalities in autism. Philos. Trans. R. Soc. Lond B Biol. Sci. 358, 405-413.

Santos, A., Rondan, C., Rosset, D. B., Da Fonseca, D., and Deruelle, C. (2008). Mr. Grimace or Ms. Smile: does categorisation affect perceptual processing in autism? Psychol. Sci. 19, 70-76.

Schachter, S., and Singer, J. E. (1962). Cognitive, social, and physiological determinants of emotional state. Psychol. Rev. 69, 379-399.

Schiller, D., Levy, I., Niv, Y., LeDoux, J. E., and Phelps, E. A. (2008). From fear to safety and back: reversal of fear in the human brain. J. Neurosci. 28, 11517-11525.

Schipul, S. E., Keller, T. A., and Just, M. A. (2011). Inter-regional brain communication and its disturbance in autism. Front. Syst. Neurosci. 5:10. doi:10.3389/fnsys.2011.00010

Schmahmann, J. D. (2010). The role of the cerebellum in cognition and emotion: personal reflections since 1982 on the dysmetria of thought hypothesis, and its historical evolution from theory to therapy. Neuropsychol. Rev. 20, 236-260.

Schmitz, N., Rubia, K., van Amelsvoort, T., Daly, E., Smith, A., and Murphy, D. G. M. (2008). Neural correlates of reward in autism. Br. J. Psychiatry 192, 19-24.

Schoen, S. A., Miller, L. J., BrettGreen, B. A., and Nielsen, D. M. (2009). Physiological and behavioural differences in sensory processing: a comparison of children with Autism Spectrum Disorder and Sensory Modulation Disorder. Front. Integr. Neurosci. 3:29. doi:10.3389/neuro.07.029.2009

Schopler, E., Reichler, R. J., DeVellis, R. G., and Daly, K. (1980). Toward objective classification of childhood autism: Childhood Autism Rating Scale (CARS). J. Autism Dev. Disord. 10, 91-103.

Schulte-Rüther, M., Greimel, E., Markowitsch, H. J., Kamp-Becker, I., Remschmidt, H., Fink, G. R., et al. (2011). Dysfunctions in brain networks supporting empathy: an fMRI study in adults with autism spectrum disorders. Soc. Neurosci. 6 , $1-21$.

Schultz, R. T. (2005). Developmental deficits in social perception in autism: the role of the amygdala and fusiform face area. Int. J. Dev. Neurosci. 23, 125-141.

Schultz, R. T., Grelotti, D. J., Klin, A., Kleinman, J., Van der Gaag, C., Marois, R., et al. (2003). The role of the fusiform face area in social cognition: implications for the pathobiology of autism. Philos. Trans. R. Soc. Lond. B Biol. Sci. 358, 415-427.

Schwenck, C., Mergenthaler, J., Keller, K., Zech, J., Salehi, S., Taurines, R., et al. (2011). Empathy in children with autism and conduct disorder: group-specific profiles and developmental aspects. J. Child Psychol. Psychiatry 53, 651-659.

Scott-Van Zeeland, A. A., Dapretto, M. Ghahremani, D. G., Poldrack, R. A., and Bookheimer, S. Y. (2010). Reward processing in autism. Autism Res. 3, 53-67.

Senju, A., and Johnson, M. H. (2009). Atypical eye contact in autism: models, mechanisms and development. Neurosci. Biobehav. Rev. 33, 1204-1214.

Serra, M., Minderaa, R. B., van Geert, P. L. C., and Jackson, A. E. (1999). Social-cognitive abilities in children with lesser variants of autism: skill deficits or failure to apply skills? Eur. Child Adolesc. Psychiatry 8, 301-311.

Seth, A. K., Suzuki, K., and Critchley, H. D. (2012). An interoceptive predictive coding model of conscious presence. Front. Psychol. 2:395. doi:10.3389/fpsyg.2011.00395

Shah, A., and Frith, U. (1993). Why do autistic individuals show superior performance on the block design task? J. Child Psychol. Psychiatry 34, 1351-1364.

Shamay-Tsoory, S. G. (2008). Recognition of 'fortune of others' emotions in Asperger syndrome and High Functioning Autism. J. Autism Dev. Disord. 38, 1451-1461.

Shukla, D. K., Keehn, B., and Müller, R.-A. (2011). Tract-specific analyses of diffusion tensor imaging show widespread white matter compromise in autism spectrum disorder. J. Child Psychol. Psychiatry 52, 286-295.
Sigman, M., Dissanayake, C., Corona, R., and Espinosa, M. (2003). Social and cardiac responses of young children with autism. Autism 7, 205-216.

Sigman, M. D., Kasari, C., Kwon, J., and Yirmiya, N. (1992). Responses to the negative emotions of others by autistic, mentally retarded, and normal children. Child Dev. 63, 796-807.

Silani, G., Bird, G., Brindley, R., Singer, T., Frith, C., and Frith, U. (2008). Levels of emotional awareness and autism: an fMRI study. Soc. Neurosci. 3, 97-112.

Sims, T. B., Van Reekum, C. M., Johnstone, T., and Chakrabarti, B. (2012). How reward modulates mimicry: EMG evidence of greater facial mimicry of more rewarding happy faces. Psychophysiology 49, 998-1004.

Singer, T. (2006). The neuronal basis and ontogeny of empathy and mind reading: review of literature and implications for future research. Neurosci. Biobehav. Rev. 30, 855-863.

Singer, T., and Lamm, C. (2009). The social neuroscience of empathy. Ann. N. Y. Acad. Sci. 1156, 81-96.

Smalley, S. L., and Asarnow, R. F. (1990). Brief report: cognitive subclinical markers in autism. J. Autism Dev. Disord. 20, 271-278.

Smith, A. (2009). Emotional empathy in autism spectrum conditions: weak, intact, or heightened? J. Autism Dev. Disord. 39, 1747-1748.

Snow, M. E., Hertzig, M. E., and Shapiro, T. (1987). Expression of emotion in young autistic children. J. Am. Acad. Child Adolesc. Psychiatry 26, 836-838.

Solomon, M., Smith, A. C., Frank, M. J., Stanford, L., and Carter, C. S. (2011). Probabilistic reinforcement learning in adults with autism spectrum disorders. Autism Res. 4, 109-120.

South, M., Larson, M. J., White, S. E., Dana, J., and Crowley, M. J. (2011). Better fear conditioning is associated with reduced symptom severity in autism spectrum disorders. Autism Res. 4, 1-10.

South, M., Newton, T., and Chamberlain, P. D. (in press). Delayed reversal learning and association with repetitive behaviour in autism spectrum disorders. Autism Res. [Epub ahead of print].

South, M., Ozonoff, S., Suchy, Y., Kesner, R. P., McMahon, W. M., and Lainhart, J. E. (2008). Intact emotion facilitation for non-social stimuli in autism: is amygdala impairment in autism specific for social information? J. Int. Neuropsychol. Soc. 14, 42-54. 
Speer, L. L., Cook, A. E., McMahon, W. M., and Clark, E. (2007). Face processing in children with autism. Autism 11, 263-275.

Spezio, M. L., Adolphs, R., Hurley, R. S. E., and Piven, J. (2007). Analysis of face gaze in autism using "bubbles." Neuropsychologia 45, 144-151.

Stanfield, A. C., McIntosh, A. M., Spencer, M. D., Phillip, R., Gaur, S., and Lawrie, S. M. (2008). Towards a neuroanatomy of autism: a systematic review and meta-analysis of structural magnetic resonance imaging studies. Eur. Psychiatry 23, 289-299.

Stel, M., van den Heuvel, C., and Smeets, R. C. (2008). Facial feedback mechanisms in autistic spectrum disorders. J. Autism Dev. Disord. 38, 1250-1258.

Stevens, S., and Gruzelier, J. (1984). Electrodermal activity to auditory stimuli in autistic, retarded and normal children. J. Autism Dev. Disord. 14, 245-260.

Strick, P. L., Dum, R. P., and Fiez, J. A. (2009). Cerebellum and nonmotor function. Annu. Rev. Neurosci. 32, 413-434.

Sugranyes, G., Kyriakopoulos, M., Corrigall, R., Taylor, E., and Frangou, S. (2011). Autism spectrum disorders and schizophrenia: meta-analysis of the neural correlates of social cognition. PLoS ONE 6:e25322. doi:10.1371/journal.pone.0025322

Tani, P., Lindberg, N., Joukamaa, M., Nieminen-von Wendt, T., von Wendt, L., Appelberg, B., et al. (2004). Asperger syndrome, alexithymia and perception of sleep. Neuropsychobiology 49, 64-70.

Tantam, D., Monaghan, L., Nicholson, H., and Sterling, J. (1989). Autistic children's ability to interpret faces: a research note. J. Child Psychol. Psychiatry 30, 623-630.

Tardif, C., Laine, F., Rodriguez, M., and Gepner, B. (2007). Slowing down presentation of facial movements and vocal sounds enhances facial expression recognition and induces facial-vocal imitation in children with autism. J. Autism Dev. Disord. 37, 1469-1484.

Teunisse, J.-P., and de Gelder, B. (2001). Impaired categorical perception of facial expressions in high-functioning adolescents with autism. Child Neuropsychol. 7, 1-14.

Toichi, M., and Kamio, Y. (2003). Paradoxical autonomic response to mental tasks in autism. J. Autism Dev. Disord. 33, 417-426.

Tracy, J. L., Robins, R. W., Schriber, R. A., and Solomon, M. (2011). Is emotion recognition impaired in individuals with autism spectrum disorders? J. Autism Dev. Disord. 41, 102-109.

Trevarthen, C. (1979). "Communication and cooperation in early infancy: a description of primary intersubjectivity," in Before speech: The Beginning of Interpersonal Communication, ed. M. Bullowa (Cambridge: Cambridge University Press), 321-347.

Uttl, B., Ohta, N., and Siegenthaler, A. L. (eds). (2006). Memory and Emotion: Interdisciplinary Perspectives. Oxford: Blackwell Publishing.

van Engeland, H. (1984). The electrodermal orienting response to auditive stimuli in autistic children, normal children, mentally retarded children, and child psychiatric patients. J. Autism Dev. Disord. 14, 261-279.

van Engeland, H., Roelofs, J. W., Verbaten, M. N., and Slangen, J. L. (1991). Abnormal electrodermal reactivity to novel visual stimuli in autistic children. Psychiatry Res. 38, 27-38.

Valenza, E., Simion, F., Cassia, V. M., and Umiltà, C. (1996). Face preference at birth. J. Exp. Psychol. Hum. Percept. Perform. 22, 892-903.

Vissers, M. E., Cohen, M. X., and Geurts, H. M. (2012). Brain connectivity and high functioning autism: a promising path of research that needs refined models, methodological convergence, and stronger behavioural link. Neurosci. Biobehav. Rev. 36, 604-625.

Volkmar, F. R., Lord, C., Bailey, A., Schultz, R. T., and Klin, A. (2004). Autism and pervasive developmental disorders. J. Child Psychol. Psychiatry 45, 135-170.

Vouloumanos, A., and Werker, J. F. (2004). Tuned to the signal: the privileged status of speech for young infants. Dev. Sci. 7, 270-276.

Vuilleumier, P. (2005). How brains beware: neural mechanisms of emotional attention. Trends Cogn. Sci. (Regul. Ed.) 9, 585-594.

Vuilleumier, P. (2009). "The role of the human amygdala in perception and attention," in The Human Amygdala, eds P. J. Whalen and E. A. Phelps (New York: The Guilford Press), 220-249.

Wallace, S., Coleman, M., and Baily, A. (2008). Face and object processing in autism spectrum disorder. Autism Res. 1, 43-51.

Wang, A. T., Dapretto, M., Hariri, A. R., Sigman, M., and Bookheimer, S. Y. (2004). Neural correlates of facial affect processing in children and adolescents with autism spectrum disorder. J. Am. Acad. Child Adolesc. Psychiatry 43, 481-490.

Weeks, S. J., and Hobson, R. P. (1987). The salience of facial expression for autistic children. J. Child Psychol. Psychiatry 28, 137-152.

Weigelt, S., Koldewyn, K., and Kanwisher, N. (2012). Face identity recognition ain autism spectrum disorders: a review of behavioural studies. Neurosci. Biobehav. Rev. 36, 1060-1084.

Weng, S.-J., Carrasco, M., Swartz, J. R., Wiggins, J. L., Kurapati, N., Liberzon, I., et al. (2011). Neural activation to emotional faces in adolescents with autism spectrum disorders. J. Child Psychol. Psychiatry 52, 296-305.

Whalen, P. J., and Phelps, E. A. (eds). (2009). The Human Amygdala. New York: Guilford.

Wicker, B., Fonlupt, P., Hubert, B., Tardif, C., Gepner, B., and Deruelle, C. (2008). Abnormal cerebral effective connectivity during explicit emotional processing in adults with autism spectrum disorder. Soc. Cogn. Affect. Neurosci. 3, 135-143.

Wiens, S. (2005). Interoception in emotional experience. Curr. Opin. Neurol. 18, 442-447.

Wilbarger, J. L., McIntosh, D. N., and Winkielman, P. (2009). Startle modulation in autism: positive affective stimuli enhance startle response. Neuropsychologia 47, 1323-1331.

Willemsen-Swinkels, S. H. N., Bakermans-Kranenburg, M. J., Buitelaar, J. K., Ijzendoorn, M. H., and van Engeland, H. (2000). Insecure and disorganised attachment in children with pervasive developmental disorder: relationship with social interaction and heart rate. J. Child Psychol. Psychiatry 41, 759-767.

Williams, D. (2010). Theory of own mind in autism. Autism 14, 474-494.

Williams, D., and Happé, F. (2010). Recognising 'social' and 'non-social' emotions in self and others: a study of autism. Autism 14, 285-304.

Wing, L. (1993). The definition and prevalence of autism: a review. Eur. Child Adolesc. Psychiatry 2, 61-74.

Wing, L., and Gould, J. (1979). Severe impairments of social interaction and associated abnormalities in children: epidemiology and classification. J. Autism Dev. Disord. 9, 11-29.

Wong, N., Beidel, D. C., Sarver, D. E., and Sims, V. (2012). Facial emotion recognition in children with high functioning Autism and children with social phobia. Child Psychiatry Hum. Dev. 43, 775-794.

Wong, T. K. W., Fung, P. C. W., Chua, S. E., and McAlonan, G. M. (2008). Abnormal spatiotemporal processing of emotional facial expressions in childhood autism: dipole source analysis of eventrelated potentions. Eur. J. Neurosci. 28, 407-416.

Wright, B., Clarke, N., Jordan, J., Young, A. W., Clarke, P., Miles, J., et al. (2008). Emotion recognition in faces and the use of visual context in young people with high-functioning autism spectrum disorders. Autism 12, 607-626.

Yirmiya, N., Kasari, C., Sigman, M., and Mundy, P. (1989). Facial expressions of affect in autistic, mentally retarded and normal children. J. Child Psychol. Psychiatry 30, 725-735.

Yirmiya, N., Sigman, M. D., Kasari, C., and Mundy, P. (1992). Empathy and cognition in high-functioning children with autism. Child Dev. 63, 150-160.

Zajonc, R. B. (1984). On the primacy of affect. Am. Psychol. 39, 117-123.

Zald, D. H. (2003). The human amygdala and the emotional evaluation of sensory stimuli. Brain Res. Rev. 41, 88-123.

Zwaigenbaum, L., Bryson, S., Rogers, T., Roberts, W., Brian, J., and Szatmari, P. (2005). Behavioural manifestations of autism in the first year of life. Int. J. Dev. Neurosci. 23, 143-152.

Conflict of Interest Statement: The author declares that the research was conducted in the absence of any commercial or financial relationships that could be construed as a potential conflict of interest.

Received: 17 July 2012; paper pending published: 15 August 2012; accepted: 11 November 2012; published online: 04 December 2012.

Citation: Gaigg SB (2012) The interplay between emotion and cognition in autism spectrum disorder: implications for developmental theory. Front. Integr. Neurosci. 6:113. doi: 10.3389/fnint.2012.00113 Copyright (c) 2012 Gaigg. This is an open-access article distributed under the terms of the Creative Commons Attribution License, which permits use, distribution and reproduction in other forums, provided the original authors and source are credited and subject to any copyright notices concerning any third-party graphics etc. 